\title{
Synthesis and cancer growth inhibitory activities of 2-fatty-alkylated pyrrolidine-3,4-diol derivatives
}

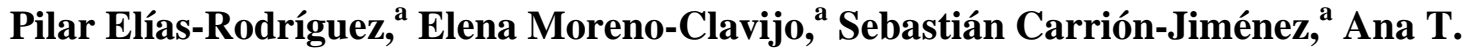 \\ Carmona, ${ }^{\mathrm{a} *}$ Antonio J. Moreno-Vargas, ${ }^{\mathrm{a}}$ Irene Caffa, ${ }^{\mathrm{b}}$ Fabrizio Montecucco, ${ }^{\mathrm{b}}$ Michele \\ Cea, ${ }^{b}$ Alessio Nencioni, ${ }^{b}$ and Inmaculada Robina ${ }^{{ }^{*}}{ }^{*}$ \\ ${ }^{a}$ Department of Organic Chemistry, University of Seville, E-41012, Seville, Spain, \\ ${ }^{b}$ Department of Internal Medicine, University of Genoa, 16132 Genoa, Italy, \\ E-mail:anatere@us.es,robina@us.es
}

Dedicated to Prof. Pierre Vogel on the occasion of his 70th anniversary

DOI: $\underline{\text { http://dx.doi.org/10.3998/ark.5550190.p008.492 }}$

\begin{abstract}
A series of new amphiphilic pyrrolidines containing dodecyl and oleyl apolar side chains were prepared and evaluated for their ability to inhibit the growth of pancreatic ductal adenocarcinoma cells in vitro. The new compounds are shown to exhibit anticancer activity at concentrations in the $\mu \mathrm{M}$ range.
\end{abstract}

Keywords: Amphiphilic compounds, pyrrolidines, iminoalditols, pancreatic cancer

\section{Introduction}

In recent years, several compounds with amphiphilic structure have been proposed as a new type of potential anticancer agents due to the lipophilic nature of their lipid chains. Series of such compounds isolated from natural sources have indeed shown promising anticancer activities. For instance, Ircinamine B, isolated from marine sponge Dactylia, ${ }^{1}$ and Melophlins $\mathrm{Q}^{2}$ isolated from Palauan marine sponge are active against mouse leukemia cell lines in the $\mu \mathrm{M}$ range. Alkylglycerols $^{3}$ from shark liver also show anticancer activity in vivo in the $\mu \mathrm{M}$ range with no toxicity on human umbilical vein endothelial cells, the best compounds bearing unsaturated 16 and 18 carbon alkyl chains. Motuporamine $\mathrm{C}$ from a marine Sponge, ${ }^{4}$ interferes with the migration of human breast carcinoma and glioma cells in culture with low toxicity in vitro. Sphingosine 4-sulfate ${ }^{5}$ from the sponge Spirastrella abata shows cytotoxic effects on several human tumor cell lines. The glycosyl ceramide, Turbostatin 1,2,3,4, ${ }^{6}$ from Asian marine mollusk Turbo stenogyrus, is active against leukemia cells in the low $\mu \mathrm{M}$ range. 
Notably, synthetic amphiphilic compounds have also shown interesting anticancer properties. As shown by Gajate and Mollinedo, ${ }^{7-9}$ edelfosine (Figure 1), a lipid analogue of lysophosphatidyl-choline induces apoptosis in several tumor cell lines through its lipid ether moiety. Once edelfosine is inside the cell, it induces selective apoptosis in cancer cells through the activation of the Fas death receptor located on the surface of cells without the participation of the corresponding Fas ligand. ${ }^{10}$
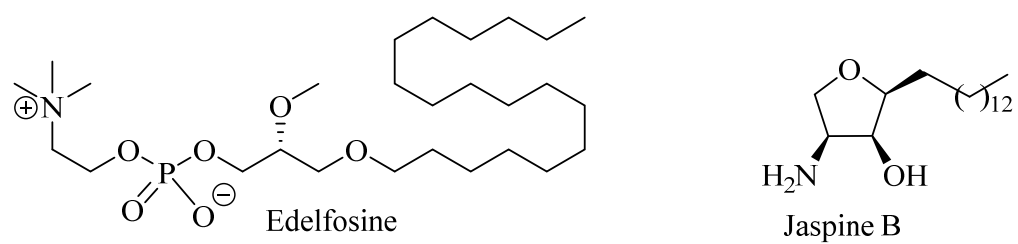

\section{Figure 1}

Other compounds such as Jaspines, having also amphiphilic character by combining a polar head (amino and hydroxy moieties) with aliphatic long chains, have shown good anticancer activities as well. Among the different diastereoisomeric Jaspines evaluated against human alveolar cell lines, Jaspine B (Figure 1) was the most active, showing cytotoxicity at nanomolar concentrations in in vitro assays. ${ }^{11}$

Due to their amphiphilic nature, glycolipids and their analogues also show therapeutic potential. Numerous glycolipid derivatives have been proposed as antibacterial/antiviral agents, ${ }^{12,13}$ cell adhesion mediators, ${ }^{14}$ and oral drug carriers. ${ }^{15}$ In the past few years, glycolipids have also been proposed as new potential anticancer agents due to the lipophilic nature of their aglycones. A variety of synthetic glycolipids have been prepared and their anticancer properties evaluated. Thus, oleyl $N$-acetyl- $\alpha$ - and $\beta$-D-glucosaminides and their thioglycosyl analogues 1a and $\mathbf{1 b}$ (Figure 2) exhibited antimitotic activity on rat glioma (C6) and human lung carcinoma (A549) cell cultures in the $\mu \mathrm{M}$ range. ${ }^{16,17}$ Triazologlycolipids 2 showed cytotoxicity against a panel of cancer cell lines in the $\mu \mathrm{M}$ range. ${ }^{18}$
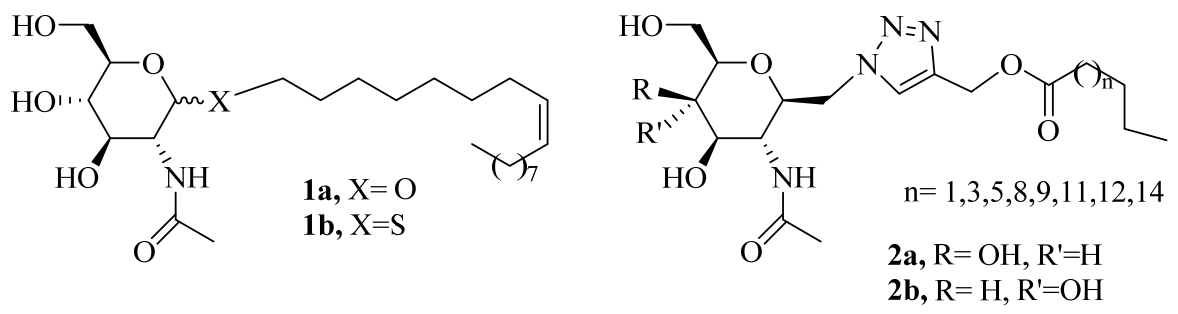

\section{Figure 2}

Derivatization of iminosugars with aliphatic side chains has been extensively studied in order to improve their biological activity, lipophilicity and bioavailability. ${ }^{19}$ For instance $N$-nonyl-1- 
deoxynojirimycin inhibits hepatitis $\mathrm{B}$ virus in cell based assays. ${ }^{20} \alpha-1-C$-Alkyl-1deoxynojirimycin derivatives have shown inhibitory activity toward intestinal isomaltase and their potency was highly dependent on the alkyl chain length. ${ }^{21} \mathrm{~N}$-alkylated-D-fagomine derivatives 3 and $N$-alkylated hydroxylated pyrrolidine 4 (Figure 3) bearing a long alkyl chain, not only presented an improved inhibitory selectivity towards $\alpha$-D-glucosidase and $\alpha$-Lfucosidase, respectively, but also exhibited enhanced cytotoxic activities on a panel of cancer cell lines compared to their non-alkylated progenitors. ${ }^{22}$ Other $N$-alkylated pyrrolidine derivatives such as $5^{23}$ and $\mathbf{6}^{24,25}$ presented interesting inhibition against $\mathrm{N}$ acetylglucosaminidases and $\alpha$-mannosidases, respectively.<smiles>CCCN1CC[C@H](O)[C@H](O)C1CO</smiles>

3

$\mathrm{n}=1,3,5,7,9$

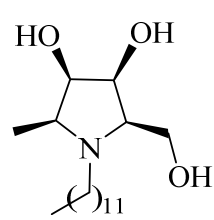

4

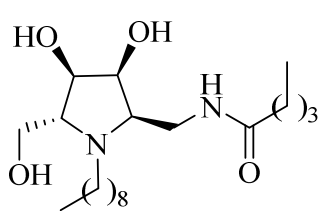

5<smiles>CC(C)NCC1N[C@H](CO)[C@@H](O)[C@H]1O</smiles>

6<smiles>[R]OC[C@@H]1NC[C@@H](O)[C@H]1O</smiles>

7, $\mathrm{R}=\mathrm{n}-\mathrm{C}_{14} \mathrm{H}_{29}$,

$\mathbf{8}, \mathrm{R}=$ palmitoleyl $\left(=c i s-\Delta^{9}-\mathrm{C}_{16} \mathrm{H}_{31}\right)$,

9, $\mathrm{R}=$ oleyl $\left(=\right.$ cis $\left.-\Delta^{9}-\mathrm{C}_{18} \mathrm{H}_{35}\right)$,

10, $\mathrm{R}=$ linoleyl $\left(=c i s, c i s-\Delta^{9,12} \mathrm{C}_{18} \mathrm{H}_{33}\right)$,

11, $\mathrm{R}=$ linolenyl $\left(=\right.$ cis, cis, cis- $\left.\Delta^{9,12,15} \mathrm{C}_{18} \mathrm{H}_{31}\right)$,

12, $\mathrm{R}=$ octadecyl

Figure 3

5-O-Alkyl 1,4-dideoxy-1,4-imino-D-ribitols bearing different long alkyl chains 7-12 (Figure 3) were evaluated as enzyme inhibitors and for their toxicity on solid and hematological malignancies showing activities in the $\mu \mathrm{M}$ range. ${ }^{26,27}$ Even though these compounds are not inhibitors of $\alpha$-mannosidases, they show promising cytotoxicity on solid and hematological malignancies, their activity depending on the length of the alkyl side chain. The oleyl derivative 9 and its C-18 analogues, linoleyl 10, linolenyl 11 and octadecyl 12, exhibited the most potent anti-cancer activity, with oleyl-conjugate 9 being the most efficient in killing tumor cells. These results indicated that the side chain and the number and position of the unsaturations play a role in determining the biological properties of this class of compounds. The anticancer activities increased with the length of the alkyl chain, in accordance with the reported data for other iminosugars $^{22}$ and with the hypothesis that a higher lipophilicity would facilitate compound transport through the cell membrane.

Compound 9 was chosen as representative of the new class of compounds because of its interesting anticancer activities against breast, lung, prostate cancer, and glioblastoma cells in the $\mu \mathrm{M}$ range $\left(\mathrm{IC}_{50}\right.$ between 2 and $\left.21 \mu \mathrm{M}\right){ }^{26,27}$ 


\section{Results and Discussion}

The promising results shown by compound $\mathbf{9}$ and derivatives, prompted us to explore further structural variations in order to improve their anticancer properties, in particular in pancreatic cancer cell lines. Thus, different series of compounds bearing amphiphilic character were prepared for structure-activity relationship studies by combining polyhydroxylated pyrrolidines with 2-fatty-alkyl moieties.

We report herein the synthesis of a series of this type of compounds starting from different sugars as source of chirality and the results of their evaluation in terms of toxicity in pancreatic cancer cell lines. The structural variations of the new compounds are shown in Figure 4. The diversity at the new structures will allow us to examine the role of different configurations at the stereogenic centers, the type of linker (X), the distance between the side chain and the pyrrolidine skeleton and the role of different functionalities at the nitrogen atom on their anticancer activity.

$$
\begin{aligned}
& \mathrm{R}=\mathrm{H}, \mathrm{CH}_{3}, \mathrm{CH}_{2} \mathrm{OH} \\
& \mathrm{R}^{1}=\mathrm{H}, \mathrm{Bu} \\
& \mathrm{R}^{2}=\text { oleyl, } \mathrm{C}_{12} \mathrm{H}_{25} \\
& \mathrm{X}=\text { triazole, } \mathrm{NHCO} \\
& \mathrm{n}=1,2 \\
& \mathrm{R}^{3}=\mathrm{H}, \mathrm{C}\left(\mathrm{CH}_{3}\right)_{2}
\end{aligned}
$$

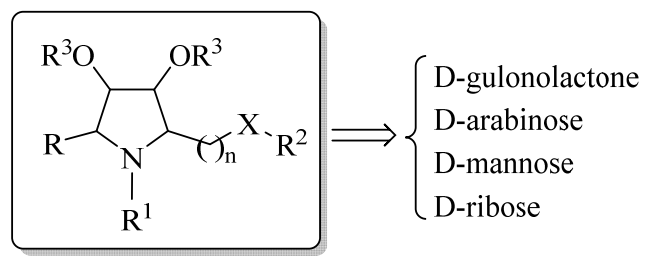

Figure 4. Structural variations for new amphiphilic pyrrolidine-3,4-diol derivatives.

Thus, compound 19 was prepared from D-ribose as outlined in Scheme 1. Starting from the known D-ribose derivative $\mathbf{1 3},^{28}$ reaction with ethyl triphenylphosphoranylidene acetate in dichloromethane at reflux afforded a mixture of alkenes 14 and $\mathbf{1 5}$ in $86 \%$ yield and a ratio $E: Z$ $1: 3.6$. The stereoselectivity in the Wittig reaction was in accordance with that described in the literature for other ribo-lactols. ${ }^{29}$ Mesylation of the free $\mathrm{OH}$ group in both alkenes followed by treatment with ammonia in ethanol led to pyrrolidine 16 as unique product (94\% yield), through tandem conjugate addition-internal $\mathrm{S}_{\mathrm{N}} 2$ displacement. Reductive amination with butanal, ester hydrolysis and amide coupling with oleyl amine in the presence of PyBOP and DIPEA afforded compound 18 in 30\% yield (two last steps). Deprotection with TBAF led to pyrrolidine 19 in quantitative yield. Attempts to deprotect 19 with cold TFA aq. were unsuccessful. The preparation of other acetonide protected pyrrolidines with the same configuration have been reported. ${ }^{30}$ 


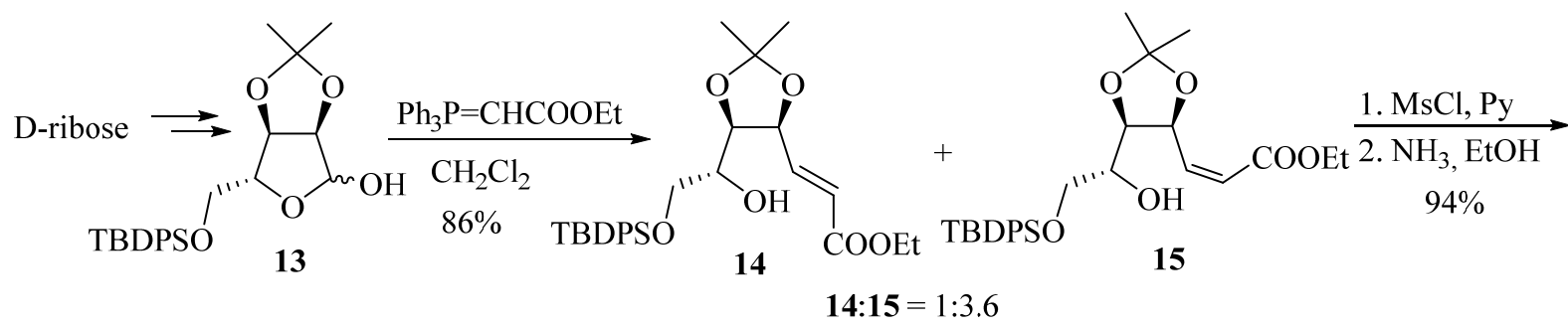<smiles>CCOC(=O)CC1NC(COC(C)C)C2OC(C)(C)OC12</smiles><smiles>CCOC(=O)CC1C2OC(C)(C)O[C@H]2C(COC(C)C)N1Br</smiles>

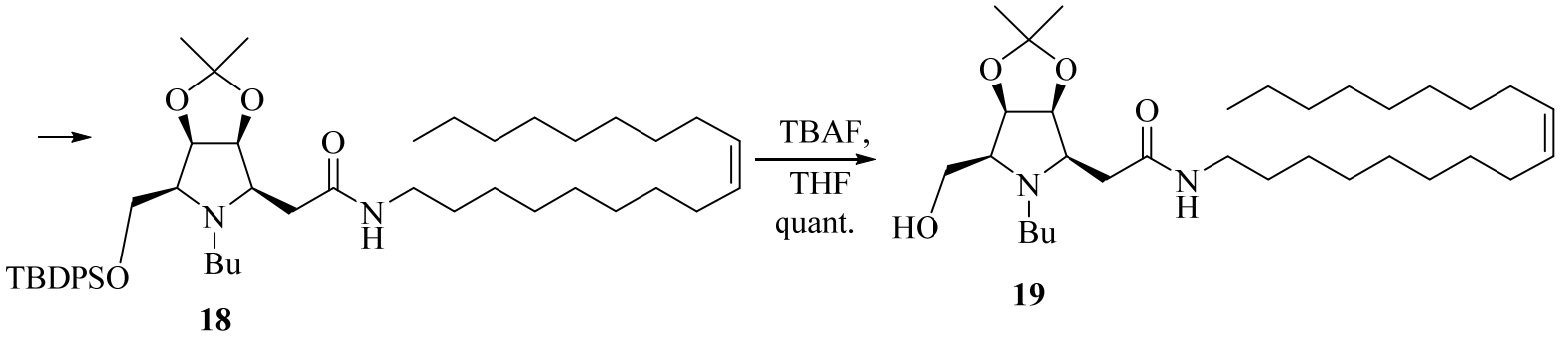

Scheme 1. Synthesis of 19.

The effect of a triazole linker between the pyrrolidine skeleton and the side chain was also studied. These compounds were prepared by click chemistry upon reaction of the corresponding pyrrolidine azides with tetradec-1-yne.

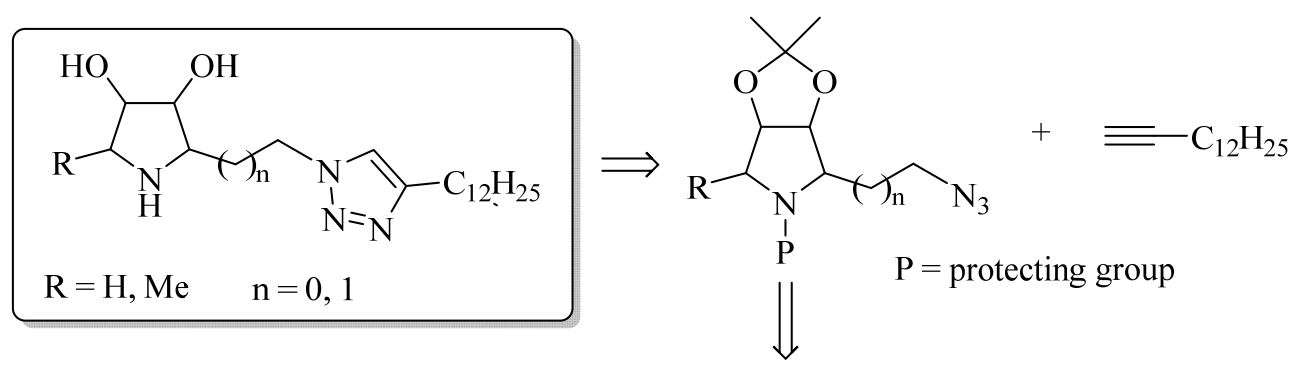

D-arabinose, D-mannose, D-gulono- $\gamma$-lactone

Figure 5. Retrosynthesis for triazole-pyrrolidine compounds.

Differently configurated pyrrolidine azides were obtained from D-mannose, D-gulono- $\gamma$ lactone and D-arabinose (Figure 5).

The preparation of the azido-pyrrolidines is outlined in Scheme 2. Starting from known aldehyde 20, ${ }^{31}$ reduction and tosylation gave derivative 21, which after displacement with 
sodium azide in DMF furnished azido derivative 22. Similarly, derivative 25 was obtained by azido displacement of the corresponding tosyl derivative $24^{32}$, obtained through oxidation, reduction and tosylation of known diol $23 .{ }^{33}$ Derivative 28 was prepared from pyrrolidine ester 26, ${ }^{34}$ by $\mathrm{Cbz}$ protection and reduction with $\mathrm{LiAlH}_{4}$ followed by mesylation and azido displacement.

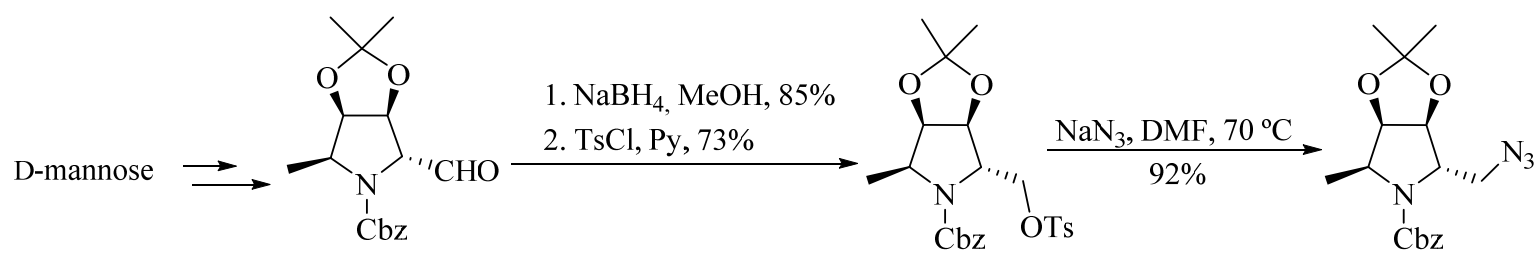

20

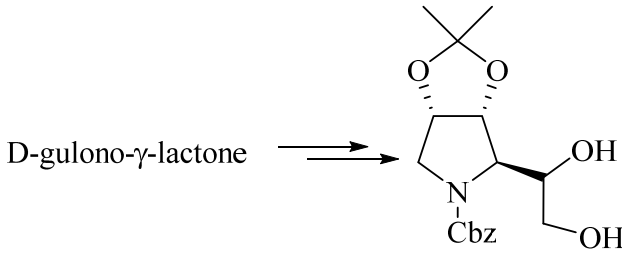

23

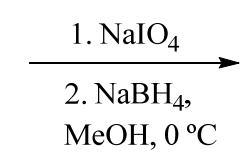

3. $\mathrm{TsCl}$, py

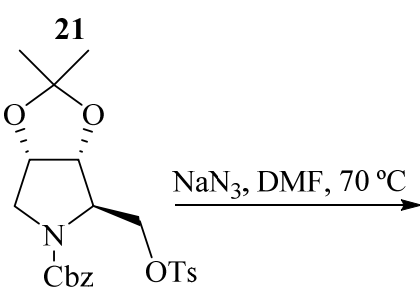

24
22<smiles>[CH2]C(C)(O)O</smiles><smiles>NCC1CCCN1C(=O)OCc1ccccc1</smiles>

25

(72\%, 4 steps)

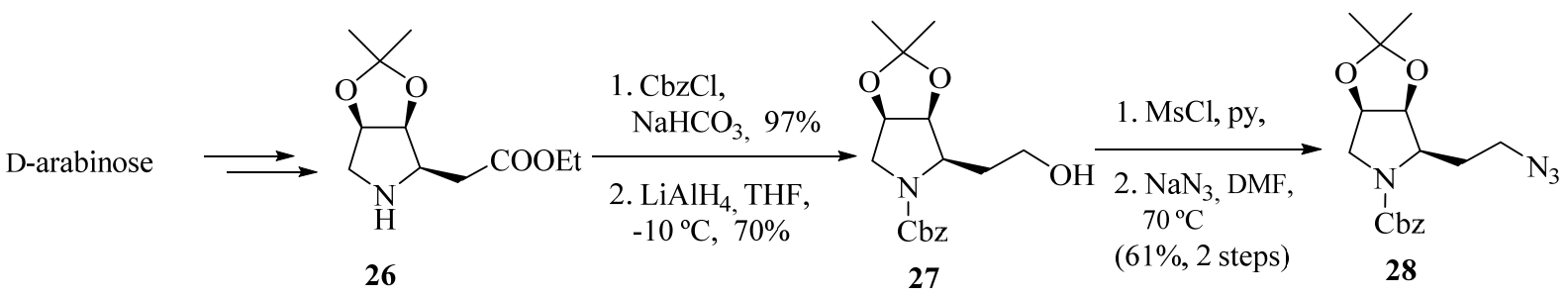

Scheme 2. Synthesis of azido-pyrrolidines.

The preparation of these azido derivatives requires benzyloxycarbonyl as $\mathrm{N}$ protecting group. The use of other carbamates as protecting groups for the preparation of the azido pyrrolidines gave unexpected results. Thus, tosylation of Boc-protected alcohol $\mathbf{2 9}$ did not lead to the corresponding tosyl derivative as expected. Instead, we mostly obtained cyclic carbamate $\mathbf{3 0}$ (Scheme 3) as confirmed by its spectral data. The ${ }^{1} \mathrm{H}$ - and ${ }^{13} \mathrm{C}$ NMR spectra of $\mathbf{3 0}$ did not show the typical signals for the tosyl and tert-butyl groups. However, a signal at 152.9 ppm was observed in the ${ }^{13} \mathrm{C}$ NMR spectra, corresponding to the carbonyl group of the carbamate.
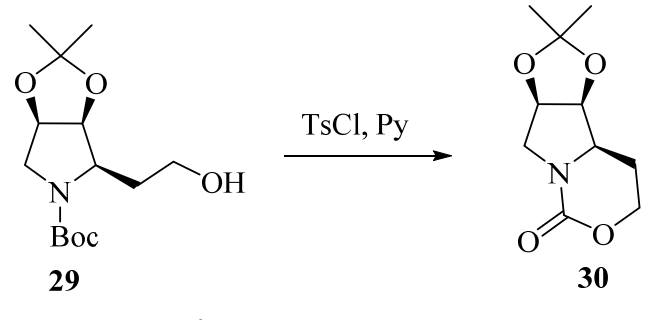

Scheme 3. Participation of the $N$-protecting group. 
The formation of cyclic carbamate 30 depends on the protecting group used in the introduction of the azide group at C-1' of the pyrrolidine. Boc protecting group as well as Fmoc exhibit a hydrogen atom at the $\beta$ position with respect to the oxygen atom, which is not the case in the $\mathrm{Cbz}$ group. Under mild basic conditions, the $\mathrm{H}$ at $\beta$ position is released with the concomitant displacement of the leaving group, promoting the formation of the cyclic carbamate, as outlined in Scheme 4.

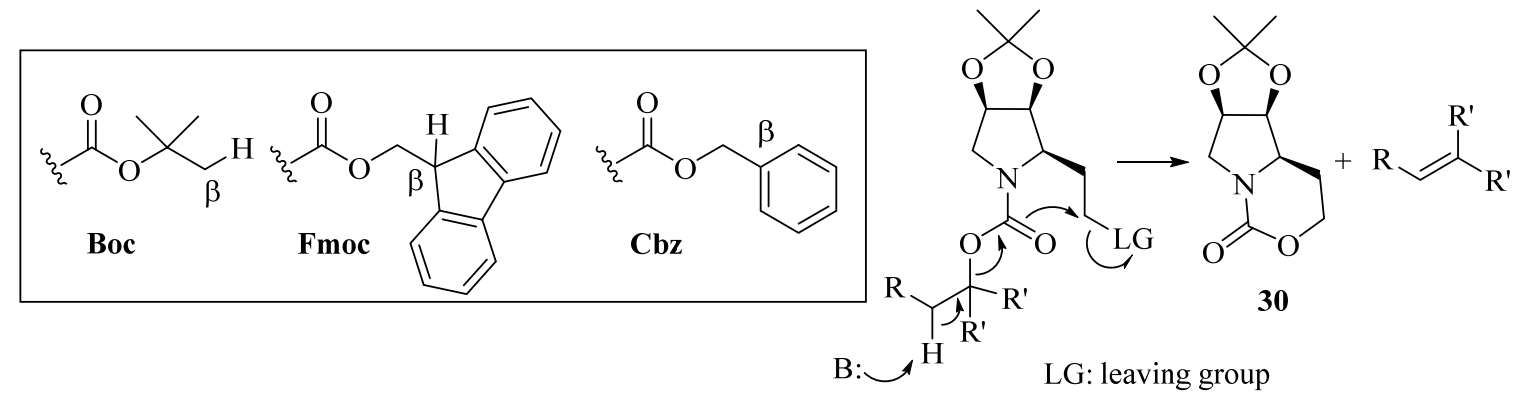

Scheme 4. Participation of carbamates on leaving group departure.

Compounds bearing a triazole moiety were prepared by copper-catalyzed dipolar cycloaddition ${ }^{35-37}$ of pyrrolidine azides (22, 25 and 28) and tetradec-1-yne in the presence of CuI and DIPEA. Subsequent deprotection reactions led to derivatives 31, 32 and 33 in good overall yields, and their structures were confirmed by NMR and HRMS spectra (Scheme 5).<smiles>C[C@H]1[C@H]2OC(C)(C)O[C@@H]2[C@H](C[NH3+])N1C(=O)O</smiles>

22<smiles>CC1(C)O[C@H]2CN(C(=O)OCc3ccccc3)[C@H](CN)[C@H]2O1</smiles>

25<smiles>CC1(C)OC2CN(C(=O)OCc3ccccc3)[C@H](CCN)[C@H]2O1</smiles>

28

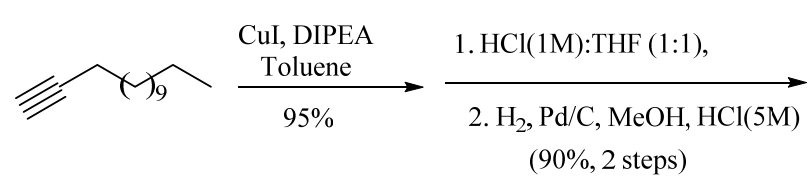

(90\%, 2 steps)

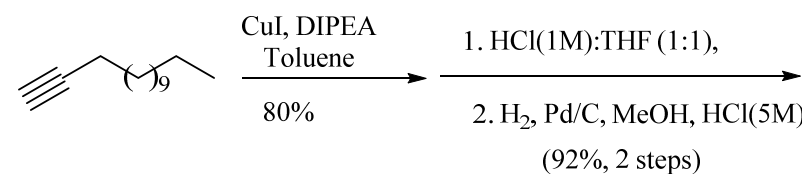

(92\%, 2 steps)

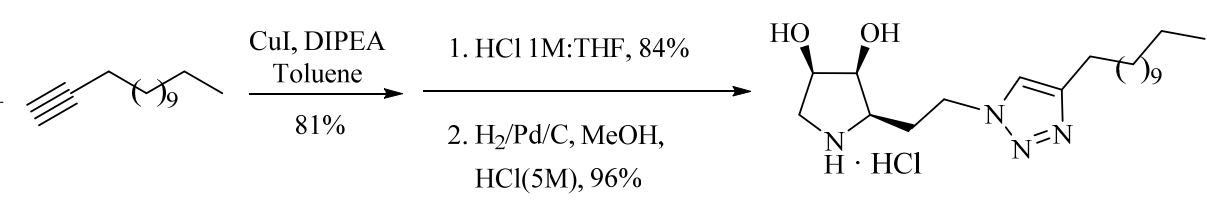

33

Scheme 5. Preparation of triazole derivatives. 
Biological evaluation. The cytotoxic activity of the new amphiphilic derivatives has been evaluated on the pancreatic cancer cell lines MiaPaCa2 and PK9. The results are summarized in Table 1 . They all exhibited antiproliferative activity in the $\mu \mathrm{M}$ range.

Although undoubtedly much research needs to be done in this area, the results shown here indicate that the amphiphilic compounds combining unsaturated alkyl chains and iminoalditols of defined configurations might be of interest for the definition of new anticancer agents to be used in the treatment of pancreatic cancer.

Table 1. $\mathrm{IC}_{50}$ of analogues of 9 toward pancreatic cancer cell lines. $\mathrm{IC}_{50}(\mu \mathrm{M})$

\begin{tabular}{llllll}
\hline & Compounds & $\mathbf{1 9}$ & $\mathbf{3 1}$ & $\mathbf{3 2}$ & $\mathbf{3 3}$ \\
\hline \multirow{3}{*}{ Cell line } & MiaPaCa2 & 3.6 & 21 & 35 & 14 \\
& PK9 & 17 & 19 & 45 & 16 \\
\hline
\end{tabular}

\section{Experimental Section}

General. Optical rotations were measured in a $1.0 \mathrm{~cm}$ or $1.0 \mathrm{dm}$ tube with a Perkin-Elmer 241MC spectropolarimeter. ${ }^{1} \mathrm{H}$ and ${ }^{13} \mathrm{C}$ NMR spectra were obtained for solutions in $\mathrm{CDCl}_{3}$, [d $\mathrm{d}_{6}$ ]DMSO and $\mathrm{CD}_{3} \mathrm{OD} ; J$ values are given in $\mathrm{Hz}$ and $\delta$ in ppm. All the assignments were confirmed by two-dimensional NMR experiments (COSY and HSQC). The LSI mass spectra were obtained using glycerol or 3-nitrobenzyl alcohol as the matrix. NMR and Mass spectra were registered in CITIUS (University of Seville). TLC was performed over silica gel $\mathrm{HF}_{254}$ (Merck), with detection by UV light charring with ninhydrin or with Pancaldi reagent $\left[\left(\mathrm{NH}_{4}\right)_{6} \mathrm{MoO}_{4}, \mathrm{Ce}\left(\mathrm{SO}_{4}\right)_{2}, \mathrm{H}_{2} \mathrm{SO}_{4}, \mathrm{H}_{2} \mathrm{O}\right]$. Silica gel 60 (Merck, 63-200 $\mu \mathrm{m}$ ) was used for preparative chromatography.

(E)- and (Z)-Ethyl 7-O-tert-butyldiphenylsilyl-2,3-dideoxy-4,5-O-isopropylidene-D-ribohept -2-enoate (14 and 15). Ethoxycarbonyltriphenylmethylenephosphorane (7 g, $20.1 \mathrm{mmol}$ ) was added to a solution of $13^{28}(3.75 \mathrm{~g}, 8.76 \mathrm{mmol})$ in dry $\mathrm{CH}_{2} \mathrm{Cl}_{2}(80 \mathrm{~mL})$ and the mixture was heated at reflux for $6 \mathrm{~h}$. After evaporation of the solvent, the residue was purified by column chromatography (ethyl acetate/petroleum ether 1:10) to afford $\mathbf{1 4}$ and $\mathbf{1 5}$ as oils $(3.74 \mathrm{~g}, 86 \%$, 14:15 = 1:3.6). Data for 14: $[\alpha]_{\mathrm{D}}^{29}+9.2\left(c 1.24, \mathrm{CH}_{2} \mathrm{Cl}_{2}\right)$; IR $\left(v \mathrm{~cm}^{-1}\right) 3462,2931,2857,1718$, 1657, $1428,1110,1059,822,740,701,614 .{ }^{1} \mathrm{H}$ NMR (300 MHz, $\left.\mathrm{CDCl}_{3}, \delta \mathrm{ppm}, J \mathrm{~Hz}\right) \delta 7.69-$ 7.64 (m, 4H, H-arom.), 7.46-7.36 (m, 6H, H-arom.), 7.12 (dd, 1H, $J_{3,2} 15.6, J_{3,4} 4.9, \mathrm{H}-3$ ), 6.14 (dd, $\left.1 \mathrm{H}, J_{2,4} 1.6, \mathrm{H}-2\right), 4.86(\mathrm{~m}, 1 \mathrm{H}, \mathrm{H}-4), 4.25-4.18$ (m, 3H, H-5, $\left.\mathrm{CH}_{2} \mathrm{CH}_{3}\right), 3.84$ (dd, $1 \mathrm{H}, J_{7 \mathrm{a}, 7 \mathrm{~b}}$ 10.4, $\left.J_{7 \mathrm{a}, 6} 3.3, \mathrm{H}-7 \mathrm{a}\right), 3.76\left(\mathrm{dd}, 1 \mathrm{H}, J_{7 \mathrm{~b}, 6} 5.5, \mathrm{H}-7 \mathrm{~b}\right), 3.63(\mathrm{~m}, 1 \mathrm{H}, \mathrm{H}-6), 2.58\left(\mathrm{~d}, 1 \mathrm{H}, J_{\mathrm{OH}, 6} 5.7\right.$, $\mathrm{OH}), 1.41,1.35\left(2 \mathrm{~s}, 3 \mathrm{H}\right.$ each, $\left.\mathrm{C}\left(\mathrm{CH}_{3}\right)_{2}\right), 1.30\left(\mathrm{t}, 3 \mathrm{H}, J_{\mathrm{H}, \mathrm{H}} 7.2, \mathrm{CH}_{2} \mathrm{CH}_{3}\right), 1.07\left(\mathrm{~s}, 9 \mathrm{H}, \mathrm{C}\left(\mathrm{CH}_{3}\right)_{3}\right)$.

${ }^{13} \mathrm{C} \mathrm{NMR}\left(75.4 \mathrm{MHz}, \mathrm{CDCl}_{3}, \delta \mathrm{ppm}\right) \delta 166.2$ (COOEt), $143.8(\mathrm{C}-3), 135.6,132.8,129.8,127.7$ (C-arom.), $122.3(\mathrm{C}-2), 109.4\left(C\left(\mathrm{CH}_{3}\right)_{2}\right), 77.4$ (C-5), 76.8 (C-4), 69.8 (C-6), 65.2 (C-7), 60.4 


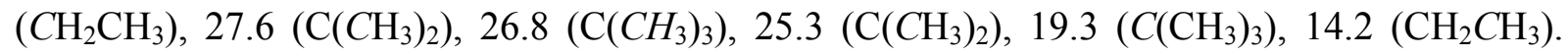
CIMS $m / z 499\left[1 \%,(\mathrm{M}+\mathrm{H})^{+}\right]$. HRCIMS $m / z$ found 499.2512, calc. for $\mathrm{C}_{28} \mathrm{H}_{39} \mathrm{O}_{6} \mathrm{Si}: 499.2516$.

Data for 15: $[\alpha]_{\mathrm{D}}^{29}+76.2\left(c 1.05, \mathrm{CH}_{2} \mathrm{Cl}_{2}\right)$; IR $\left(v \mathrm{~cm}^{-1}\right) 2931,2857,1716,1698,1427,1380$, 1190, 1055, 869, 822, 701, 615. ${ }^{1} \mathrm{H}$ NMR (300 MHz, $\left.\mathrm{CDCl}_{3}, \delta \mathrm{ppm}, J \mathrm{~Hz}\right) \delta$ 7.68-7.66 (m, 4H, H-arom.), 7.45-7.35 (m, 6H, H-arom.), 6.23 (dd, 1H, $J_{3,2} 11.7, J_{3,4} 8.4, \mathrm{H}-3$ ), 5.94 (dd, 1H, $J_{2,4}$ 1.1, H-2), $5.74(\mathrm{~m}, 1 \mathrm{H}, \mathrm{H}-4), 4.38$ (dd, $\left.1 \mathrm{H}, J_{5,4} 8.1, J_{5,6} 6.3, \mathrm{H}-5\right), 4.19$ (q, 2H, $J_{\mathrm{H}, \mathrm{H}} 6.9$, $\mathrm{CH}_{2} \mathrm{CH}_{3}$ ), 3.84-3.75 (m, 2H, H-7a, H-7b), 3.66 (m, 1H, H-6), 2.80 (d, 1H, $\left.J_{\mathrm{OH}, 6} 4.5, \mathrm{OH}\right), 1.38$, $1.35\left(2 \mathrm{~s}, 3 \mathrm{H}\right.$ each, $\left.\mathrm{C}\left(\mathrm{CH}_{3}\right)_{2}\right), 1.30\left(\mathrm{t}, 3 \mathrm{H}, \mathrm{CH}_{2} \mathrm{CH}_{3}\right), 1.06\left(\mathrm{~s}, 9 \mathrm{H}, \mathrm{C}\left(\mathrm{CH}_{3}\right)_{3}\right) .{ }^{13} \mathrm{C} \mathrm{NMR} \quad(75.4$ $\left.\mathrm{MHz}, \mathrm{CDCl}_{3}, \delta \mathrm{ppm}\right) \delta 166.1$ (COOEt), 144.6 (C-3), 135.6, 133.2, 129.7, 127.7 (C-arom.), 122.2

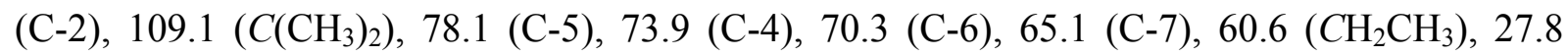

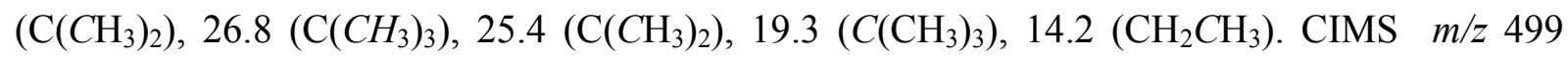
$\left[1 \%,(\mathrm{M}+\mathrm{H})^{+}\right]$. HRCIMS $m / z$ found 499.2498, calc. for $\mathrm{C}_{28} \mathrm{H}_{39} \mathrm{O}_{6} \mathrm{Si}: 499.2516$.

Ethyl 7-O-tert-butyldiphenylsilyl-2,3,6-trideoxy-3,6-imino-4,5-O-isopropylidene-L-galactoheptanoate $((2 S, 3 R, 4 S, 5 R)$-2-tert-butyldiphenylsilyloxymethyl-5-ethoxycarbonylmethyl-3,4$\boldsymbol{O}$-isopropylidene- pyrrolidine-3,4-diol) (16). A solution of 14 and 15 (2.22 g, $4.45 \mathrm{mmol})$ in dry $\mathrm{CH}_{2} \mathrm{Cl}_{2}(10 \mathrm{~mL})$ was added dropwise to a stirred solution of $\mathrm{MsCl}(1.2 \mathrm{~mL}, 16.0 \mathrm{mmol})$ in dry pyridine $(4 \mathrm{~mL})$ cooled to $0{ }^{\circ} \mathrm{C}$. After stirring at r.t. overnight, the mixture was cooled to 0 ${ }^{\circ} \mathrm{C}, \mathrm{H}_{2} \mathrm{O}(5 \mathrm{~mL})$ was added and the reaction stirred for $15 \mathrm{~min}$ at r.t. The solvent was then evaporated, the crude diluted with dichloromethane and washed with $\mathrm{H}_{2} \mathrm{O}$ and brine. The organic phase was dried, filtered and concentrated. The residue was dissolved in absolute EtOH $(45 \mathrm{~mL})$, cooled to $0{ }^{\circ} \mathrm{C}$ and saturated with $\mathrm{NH}_{3}$. After 4 days at r.t., the solvent was evaporated and the residue was treated with $\mathrm{NH}_{4} \mathrm{OH}(25 \%, 30 \mathrm{~mL})$ and extracted with $\mathrm{CH}_{2} \mathrm{Cl}_{2}(5 \times 30 \mathrm{~mL})$. The organic phase was washed with satd. aq. sol. of $\mathrm{NaHCO}_{3}(30 \mathrm{~mL})$ and $\mathrm{H}_{2} \mathrm{O}$ until neutral $\mathrm{pH}$, dried $\left(\mathrm{Na}_{2} \mathrm{SO}_{4}\right)$, filtered and concentrated. The residue was purified by column chromatography (AcOEt:petroleum ether (1:6), $\left.\mathrm{Et}_{3} \mathrm{~N}(1 \%)\right)$ to give pure 16 as an oil $(2.09 \mathrm{~g}, 94 \%)$. $[\alpha]_{\mathrm{D}}^{26}+12.3(c$ $\left.1.25, \mathrm{CH}_{2} \mathrm{Cl}_{2}\right)$; IR $\left(v \mathrm{~cm}^{-1}\right) 2930,2857,1731,1108,1091,822,739,701,615 .{ }^{1} \mathrm{H}$ NMR (300 $\mathrm{MHz}, \mathrm{CDCl}_{3}, \delta$ ppm, $J \mathrm{~Hz}$ ) $\delta$ 7.72-7.68 (m, 4H, H-arom.), 7.41-7.34 (m, 6H, H-arom.), 4.63 (dd, $\left.1 \mathrm{H}, J_{5,4} 5.7, J_{5,6} 4.1, \mathrm{H}-5\right), 4.60\left(\mathrm{dd}, 1 \mathrm{H}, J_{4,3} 4.2, \mathrm{H}-4\right), 4.15\left(\mathrm{~m}, 2 \mathrm{H}, \mathrm{CH}_{2} \mathrm{CH}_{3}\right), 3.90\left(\mathrm{dd}, 1 \mathrm{H}, J_{7 \mathrm{a}, 7 \mathrm{~b}}\right.$ $\left.10.4, J_{7 \mathrm{a}, 6} 7.1, \mathrm{H}-7 \mathrm{a}\right), 3.83$ (dd, $1 \mathrm{H}, J_{7 \mathrm{~b}, 6} 6.7, \mathrm{H}-7 \mathrm{~b}$ ), 3.17 (ddd, $1 \mathrm{H}, J_{3,2 \mathrm{~b}} 7.6, J_{3,2 \mathrm{a}} 6.4, \mathrm{H}-3$ ), 3.02 (m, 1H, H-6), 2.66 (dd, 1H, $\left.{ }^{2} J_{2 \mathrm{a}, 2 \mathrm{~b}} 17.0, \mathrm{H}-2 \mathrm{a}\right), 2.59$ (dd, 1H, H-2b), 1.81 (br s, 1H, NH), 1.39, $1.29\left(2 \mathrm{~s}, 3 \mathrm{H}\right.$ each, $\left.\mathrm{C}\left(\mathrm{CH}_{3}\right)_{2}\right), 1.26\left(\mathrm{t}, 3 \mathrm{H}, \mathrm{CH}_{2} \mathrm{CH}_{3}\right), 1.06\left(\mathrm{~s}, 9 \mathrm{H}, \mathrm{C}\left(\mathrm{CH}_{3}\right)_{3}\right) .{ }^{13} \mathrm{C} \mathrm{NMR} \quad(75.4$ $\left.\mathrm{MHz}, \mathrm{CDCl}_{3}, \delta \mathrm{ppm}\right) \delta 172.2$ (COOEt), 135.7, 135.6, 133.7, 133.6, 129.5, 127.6, 127.5 (C-

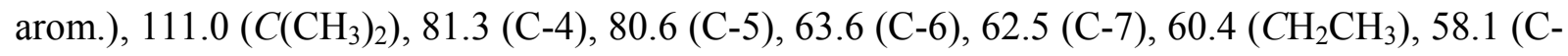

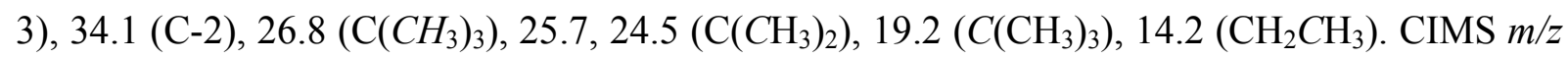
$497\left[1 \%,(\mathrm{M})^{+}\right], 440\left[50 \%,\left(\mathrm{M}-{ }^{t} \mathrm{Bu}\right)^{+}\right]$. HRCIMS $m / z$ found 497.2591 , calc. for $\mathrm{C}_{28} \mathrm{H}_{39} \mathrm{NO}_{5} \mathrm{Si}$ : 497.2598.

(2S,3R,4S,5R)- $N$-Butyl-2-tert-butyldiphenylsilyloxymethyl-5-ethoxycarbonylmethyl-3,4-Oisopropylidene-pyrrolidine-3,4-diol (17). Butanal $(0.3 \mathrm{~mL}, 3.38 \mathrm{mmol})$ and $\mathrm{NaBH}(\mathrm{OAc})_{3}(752$ $\mathrm{mg}, 3.55 \mathrm{mmol})$ were added to a solution of $16(840 \mathrm{mg}, 1.69 \mathrm{mmol})$ in 1,2-dichloroethane (10 $\mathrm{mL}$ ). The reaction mixture was stirred overnight at r.t. Then, aq. sat. sol. of $\mathrm{NaHCO}_{3}$ was added 
and the mixture extracted with $\mathrm{CH}_{2} \mathrm{Cl}_{2}$. The organic phases were dried $\left(\mathrm{Na}_{2} \mathrm{SO}_{4}\right)$ and evaporated in vacuo. Purification of the residue by column chromatography (AcOEt:petroleum ether 1:10) afforded 17 as an oil (825 mg, 88\%). [ $\alpha]_{\mathrm{D}}^{29}+1.9\left(c 1.15, \mathrm{CH}_{2} \mathrm{Cl}_{2}\right)$; IR $\left(v \mathrm{~cm}^{-1}\right)$ 2931, 2857, 1732, $1110,1087,823,738,701,613 .{ }^{1} \mathrm{H} \mathrm{NMR}\left(300 \mathrm{MHz}, \mathrm{CDCl}_{3}, \delta \mathrm{ppm}, J \mathrm{~Hz}\right) \delta$ 7.73-7.68 (m, 4H, $\mathrm{H}$-arom.), 7.42-7.34 (m, 6H, H-arom.), 4.64-4.62 (m, 2H, H-4, H-3), 4.15 (qd, 2H, ${ }^{3} J_{\mathrm{H}, \mathrm{H}} 7.1, J$

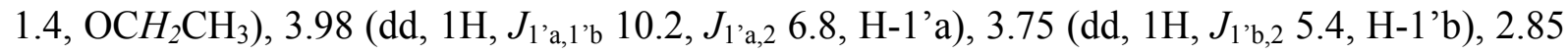
(m, 1H, H-5), 2.72-2.63 (m, 2H, H-2, H-1'”a), 2.61-2.40 (m, 3H, H-1 ' 'b, $\left.\mathrm{CH}_{2}-\mathrm{N}\right), 1.39,1.29$ (2s, $3 \mathrm{H}$ each, $\left.\mathrm{C}\left(\mathrm{CH}_{3}\right)_{2}\right), 1.25$ (t, 3H, $\left.\mathrm{OCH}_{2} \mathrm{CH}_{3}\right), 1.24-1.09$ (m, $\left.4 \mathrm{H}, \mathrm{CH}_{2} \mathrm{CH}_{2}\right), 1.05\left(\mathrm{~s}, 9 \mathrm{H}, \mathrm{C}\left(\mathrm{CH}_{3}\right)_{3}\right)$, $0.83\left(\mathrm{t}, 3 \mathrm{H},{ }^{3} J_{\mathrm{H}, \mathrm{H}} 7.2, \mathrm{CH}_{3}\right) .{ }^{13} \mathrm{C} \mathrm{NMR}\left(75.4 \mathrm{MHz}, \mathrm{CDCl}_{3}, \delta \mathrm{ppm}\right) \delta 172.4$ (COOEt), 135.7,

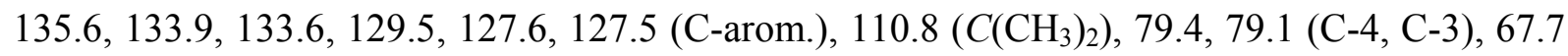
(C-2), 62.7, $62.5\left(\mathrm{C}-1\right.$ ', C-5), $60.3\left(\mathrm{OCH}_{2} \mathrm{CH}_{3}\right), 49.5\left(\mathrm{C}-1\right.$ '”), $33.2\left(\mathrm{CH}_{2}-\mathrm{N}\right), 27.1\left(\mathrm{CH}_{2}\right), 26.8$

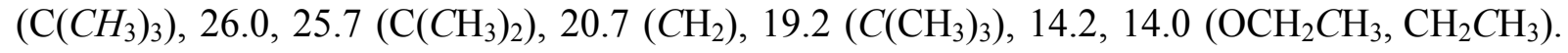
CIMS $m / z 554\left[15 \%,(\mathrm{M}+\mathrm{H})^{+}\right]$. HRCIMS $m / z$ found 554.3283, calc. for $\mathrm{C}_{32} \mathrm{H}_{48} \mathrm{NO}_{5} \mathrm{Si}: 554.3302$. (2S,3R,4S,5R)- $N$-Butyl-2-tert-butyldiphenylsilyloxymethyl-3,4-O-isopropylidene-5-oleylcarbamoylmethyl pyrrolidine-3,4-diol (18). A solution of $17(119 \mathrm{mg}, 0.23 \mathrm{mmol})$ in EtOH: $1 \mathrm{M} \mathrm{NaOH}(1: 1,3 \mathrm{~mL})$ was stirred for $2 \mathrm{~h}$ at r.t. Then, the mixture was neutralized with IRA-120 $\left(\mathrm{H}^{+}\right)$resin, filtered and concentrated. The residue thus obtained was dissolved in DMF $(2 \mathrm{~mL})$ and oleyl amine (67 mg, $0.25 \mathrm{mmol})$, DIPEA (118 $\mu \mathrm{L}, 0.69 \mathrm{mmol})$ and PyBOP (130 mg, $0.25 \mathrm{mmol}$ ) were added. After stirring at r.t. overnight, the mixture was evaporated to dryness and the residue was dissolved in $\mathrm{CH}_{2} \mathrm{Cl}_{2}$ and washed with $1 \mathrm{M} \mathrm{HCl}$, sat. aq. soln. of $\mathrm{NaHCO}_{3}$ and sat. aq. soln. of $\mathrm{NaCl}$. The dried organic phase $\left(\mathrm{MgSO}_{4}\right)$ was purified by chromatography over silica gel (AcOEt:petroleum ether 1:3) to give 18 as an oil $(53 \mathrm{mg}, 30 \%)$. $[\alpha]_{\mathrm{D}}^{29}-1.7(c 1.05$, $\left.\mathrm{CH}_{2} \mathrm{Cl}_{2}\right)$; IR $\left(\mathrm{v} \mathrm{cm}^{-1}\right) 3299,2921,2852,1643,1110,1092,823,738,701,614 .{ }^{1} \mathrm{H}$ NMR (300 $\left.\mathrm{MHz}, \mathrm{CDCl}_{3}, \delta \mathrm{ppm}, J \mathrm{~Hz}\right) \delta$ 7.73-7.67 (m, 4H, H-arom.), 7.42-7.35 (m, 6H, H-arom.), 6.56 (br t, $1 \mathrm{H}, \mathrm{NH}), 5.38-5.32(\mathrm{~m}, 2 \mathrm{H}, \mathrm{CH}=\mathrm{CH}), 4.62(\mathrm{dd}, 1 \mathrm{H}, J$ 6.5, J 4.8, H-3), 4.50 (br dd, $1 \mathrm{H}, \mathrm{H}-4)$, $3.97\left(\mathrm{dd}, 1 \mathrm{H},{ }^{2} J_{1^{\prime} \mathrm{a}, 1^{\prime} \mathrm{b}} 10.0, J_{1^{\prime} \mathrm{a}, 2} 7.0, \mathrm{H}-1\right.$ 'a), $3.76\left(\mathrm{dd}, 1 \mathrm{H}, J_{1^{\prime} \mathrm{b}, 2} 5.0, \mathrm{H}-1\right.$ 'b), 3.20 (q, 2H, $J_{\mathrm{H}, \mathrm{H}} 6.4$, $\mathrm{CH}_{2}-\mathrm{NH}$ ), 2.83 (m, 1H, H-5), 2.70 (m, 1H, H-2), 2.63-2.35 (m, 4H, H-1'’a, H-1' 'b, CH $H_{2}-\mathrm{N}$ ), 2.02-1.98 (m, 4H, $\left.\mathrm{CH}_{2}-\mathrm{CH}=\mathrm{CH}-\mathrm{CH}_{2}\right), 1.39\left(\mathrm{~s}, 3 \mathrm{H}, \mathrm{C}\left(\mathrm{CH}_{3}\right)_{2}\right), 1.48-1.09\left(\mathrm{~m}, 31 \mathrm{H}, 14 \mathrm{CH}_{2}\right.$, $\left.\mathrm{C}\left(\mathrm{CH}_{3}\right)_{2}\right), 1.05\left(\mathrm{~s}, 9 \mathrm{H}, \mathrm{C}\left(\mathrm{CH}_{3}\right)_{3}\right), 0.88\left(\mathrm{t}, 3 \mathrm{H}, J_{\mathrm{H}, \mathrm{H}} 6.3, \mathrm{CH}\right), 0.83\left(\mathrm{t}, 3 \mathrm{H}, J_{\mathrm{H}, \mathrm{H}} 7.2, \mathrm{CH}_{3}\right) .{ }^{13} \mathrm{C}$ NMR (75.4 MHz, $\left.\mathrm{CDCl}_{3}, \delta \mathrm{ppm}\right) \delta 171.3(\mathrm{C}=\mathrm{O}), 135.7,135.5,133.7,133.5$ (C-arom.), 129.9,

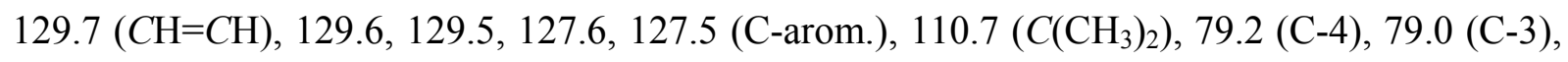
$67.6(\mathrm{C}-2), 63.4(\mathrm{C}-5), 62.5\left(\mathrm{C}-1\right.$ '), $49.4\left(\mathrm{C}-1{ }^{\prime}\right.$ '), $35.2\left(\mathrm{CH}_{2}-\mathrm{N}\right), 32.6\left(\mathrm{CH}_{2}\right), 31.9\left(\mathrm{CH}_{2}\right), 29.7-$ $\left.29.2\left(\mathrm{CH}_{2}\right), 27.2,27.1\left(\mathrm{CH}_{2}\right), 26.7\left(\mathrm{C}_{\left.\left(\mathrm{CH}_{3}\right)_{3}\right)}\right), 25.7,25.0\left(\mathrm{C}_{(\mathrm{CH}}\right)_{2}\right), 22.6\left(\mathrm{CH}_{2}\right), 20.6\left(\mathrm{CH}_{2}\right), 19.1$ $\left(C\left(\mathrm{CH}_{3}\right)_{3}\right), 14.1,14.0\left(2 \mathrm{CH}_{3}\right)$. CIMS $m / z 775\left[100 \%,(\mathrm{M}+\mathrm{H})^{+}\right]$. HRCIMS $m / z$ found 775.5804 , calc. for $\mathrm{C}_{48} \mathrm{H}_{79} \mathrm{~N}_{2} \mathrm{O}_{4} \mathrm{Si}: 775.5809$.

(2S,3R,4S,5R)- $N$-Butyl-2-hydroxymethyl-3,4-O-isopropylidene-5-oleylcarbamoylmethyl pyrrolidine-3,4-diol (19). TBAF (1 M in THF, $0.25 \mathrm{~mL}$ ) was added to a solution of 18 (59.4 $\mathrm{mg}, 0.071 \mathrm{mmol})$ in THF $(1 \mathrm{~mL})$. After stirring at r.t. for $5 \mathrm{~h}$, the solvent was evaporated and the residue purified by chromatography column over silica gel (ether/acetone 50:1) to afford $\mathbf{1 9}$ as 
an oil (38 mg, quant.). $[\alpha]_{\mathrm{D}}^{28}-10.6\left(c 1.04, \mathrm{CH}_{2} \mathrm{Cl}_{2}\right)$; IR $\left(v \mathrm{~cm}^{-1}\right) 3306(\mathrm{OH}, \mathrm{NH}), 2924,2855$, $1648(\mathrm{C}=\mathrm{O}), 1458,1206,1043,713 .{ }^{1} \mathrm{H}$ NMR $\left(300 \mathrm{MHz}, \mathrm{CDCl}_{3}, \delta \mathrm{ppm}, J \mathrm{~Hz}\right) \delta 6.54$ (br t, $1 \mathrm{H}$, $\mathrm{NH}), 5.39-5.32(\mathrm{~m}, 2 \mathrm{H}, \mathrm{CH}=\mathrm{CH}), 4.69(\mathrm{dd}, 1 \mathrm{H}, J 5.1, J 6.3, \mathrm{H}-3$ or H-4), 4.58 (dd, 1H, $J$ 5.1, $J$ 6.0, H-3 or H-4), 3.94 (dd, 1H, ${ }^{2} J_{1^{\prime} \mathrm{a}, 1^{\prime} \mathrm{b}} 11.7, J_{1^{\prime} \mathrm{a}, 2} 2.5, \mathrm{H}-1$ 'a), 3.82 (dd, 1H, $J_{1^{\prime} \mathrm{b}, 2} 5.8, \mathrm{H}-1^{\prime}$ 'b), 3.25-3.18 (m, 2H, CH ${ }_{2}-\mathrm{NH}$ ), 3.02 (br s, $\left.1 \mathrm{H}, \mathrm{H}-5\right)$, 2.68-2.45 (m, 5H, H-2, H-1 ' a, H-1 ' 'b, $\mathrm{CH}_{2^{-}}$ $\mathrm{N}), 2.07-1.91\left(\mathrm{~m}, 4 \mathrm{H}, \mathrm{CH}_{2}-\mathrm{CH}=\mathrm{CH}-\mathrm{CH}_{2}\right), 1.49\left(\mathrm{~s}, 3 \mathrm{H}, \mathrm{C}\left(\mathrm{CH}_{3}\right)_{2}\right), 1.36-1.22\left(\mathrm{~m}, 36 \mathrm{H}, 14 \mathrm{CH}_{2}\right.$, $\left.\mathrm{C}\left(\mathrm{CH}_{3}\right)_{2}\right), 0.94-0.83\left(\mathrm{~m}, 6 \mathrm{H}, 2 \mathrm{CH}_{3}\right) .{ }^{13} \mathrm{C} \mathrm{NMR}\left(75.4 \mathrm{MHz}, \mathrm{CDCl}_{3}, \delta \mathrm{ppm}\right) \delta 171.0(\mathrm{C}=\mathrm{O})$,

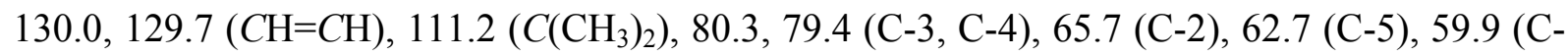
1'), $48.8\left(\mathrm{C}-1\right.$ ' '), $39.4\left(\mathrm{CH}_{2}-\mathrm{NH}\right), 31.9\left(\mathrm{CH}_{2}-\mathrm{N}\right), 29.7-20.7\left(16 \mathrm{CH}_{2}, \mathrm{C}\left(\mathrm{CH}_{3}\right)_{2}\right), 14.1,13.9\left(2 \mathrm{CH}_{3}\right)$. CIMS $m / z 537\left[100 \%,(\mathrm{M}+\mathrm{H})^{+}\right]$. HRCIMS $m / z$ found 537.4637, calc. for $\mathrm{C}_{32} \mathrm{H}_{61} \mathrm{~N}_{2} \mathrm{O}_{4}: 537.4631$. (2S,3S,4R,5S)- $N$-Benzyloxycarbonyl-2-tosyloxymethyl-3,4-O-isopropylidene-5-methylpyrrolidine-3,4- diol (21). $\mathrm{NaBH}_{4}(0.43 \mathrm{~g}, 4.75 \mathrm{mmol})$ was added to a solution of $\mathbf{2 0}^{31}$ (735 mg, $2.30 \mathrm{mmol})$ in $\mathrm{MeOH}(11 \mathrm{~mL})$, and the mixture stirred at r.t. for $20 \mathrm{~min}$. Then, $\mathrm{AcOH}(0.1 \mathrm{~mL})$ was added and the mixture subsequently diluted with AcOEt and washed with sat. aq. soln. of $\mathrm{NaHCO}_{3}$. The organic phases were dried, filtered and concentrated. The residue was purified by chromatography column over silica gel (AcOEt:petroleum ether 1:2) to afford the corresponding alcohol $(0.63 \mathrm{~g}, 85 \%)$. To a $0{ }^{\circ} \mathrm{C}$ solution of the alcohol $(383 \mathrm{mg}, 1.19 \mathrm{mmol})$ in dry pyridine $(10$ $\mathrm{mL})$ was slowly added $\mathrm{TsCl}(0.69 \mathrm{~g}, 3.56 \mathrm{mmol})$. After stirring at r.t for $4.5 \mathrm{~h}$, the mixture was cooled to $0{ }^{\circ} \mathrm{C}$, water was slowly added $(0.5 \mathrm{~mL})$, and the mixture was allowed to warm to r.t. Solvent was then removed, and the residue was diluted with AcOEt, washed with $\mathrm{HCl}(1 \mathrm{~N})$, sat. aq. soln. of $\mathrm{NaHCO}_{3}$ and brine, dried, filtered, and concentrated. Purification by chromatography column (AcOEt:cyclohexane 1:4) afforded 21 as an oil (414 mg, 73\%). $[\alpha]_{\mathrm{D}}^{28}+18.2$ (c 0.51 , $\left.\mathrm{CH}_{2} \mathrm{Cl}_{2}\right)$. IR $v_{\max } 2986,2938,1698(\mathrm{C}=\mathrm{O}), 1356(\mathrm{~S}=\mathrm{O}), 1175,814 \mathrm{~cm}^{-1} .{ }^{1} \mathrm{H}$ NMR $(300 \mathrm{MHz}$, DMSO- $\left.d_{6}, 363 \mathrm{~K}, \delta \mathrm{ppm}\right) \delta$ 7.78-7.73 (m, $2 \mathrm{H}, \mathrm{H}$-arom. of Ts), 7.47-7.44 (m, 2H, H-arom. of Ts), 7.39-7.28 (m, 5H, H-arom.), 5.09 (d, $1 \mathrm{H},{ }^{2} J_{\mathrm{H}, \mathrm{H}} 12.7, \mathrm{CH}_{2}$ of Cbz), $5.04\left(\mathrm{~d}, 1 \mathrm{H}, \mathrm{CH}_{2}\right.$ of Cbz), 4.60

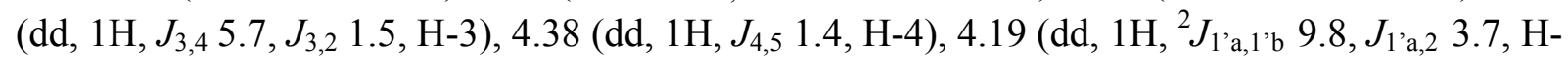
1'a ), 4.09 (dd, 1H, $J_{1 ' \text { 'b, }}$ 5.9, H-1'b), 4.05 (m, 1H, H-2), 3.98 (qd, 1H, $J_{5, \mathrm{Me}} 6.9, \mathrm{H}-5$ ), 2.42 (s, $3 \mathrm{H}, \mathrm{Me}$ of Ts $), 1.33,1.25\left(2 \mathrm{~s}, 3 \mathrm{H}\right.$ each, $\left.\mathrm{C}\left(\mathrm{CH}_{3}\right)_{2}\right), 1.13(\mathrm{~d}, 3 \mathrm{H}, \mathrm{Me}) .{ }^{13} \mathrm{C} \mathrm{NMR}(75.4 \mathrm{MHz}$, DMSO- $\left.d_{6}, 363 \mathrm{~K}, \delta \mathrm{ppm}\right) \quad \delta 153.3(\mathrm{C}=\mathrm{O}$ of $\mathrm{Cbz}), 144.6,136.2,132.1,129.6,127.8,127.3$, 127.0, 126.7, 125.1 (C-arom.), $110.8\left(C\left(\mathrm{CH}_{3}\right)_{2}\right), 84.2(\mathrm{C}-4), 80.5(\mathrm{C}-3), 68.4(\mathrm{C}-1$ ') $), 65.9\left(\mathrm{CH}_{2}\right.$ of Cbz), 62.8 (C-2), 59.6 (C-5), 26.6, $24.6\left(\mathrm{C}\left(\mathrm{CH}_{3}\right)_{2}\right), 20.5$ (Me of Ts), 18.2 (Me). CIMS m/z 476 $\left[1 \%,(\mathrm{M}+\mathrm{H})^{+}\right], 340\left[10 \%,(\mathrm{M}-\mathrm{Cbz}+\mathrm{H})^{+}\right]$. HRCIMS $\mathrm{m} / z$ found 476.1736 , calcd. for $\mathrm{C}_{24} \mathrm{H}_{30} \mathrm{NO}_{7} \mathrm{~S}$ $[\mathrm{M}+\mathrm{H}]^{+}: 476.1743$.

(2S,3S,4R,5S)- $N$-Benzyloxycarbonyl-2-azidomethyl-3,4-O-isopropylidene-5-methylpyrrolidine-3,4-diol (22). $\mathrm{NaN}_{3}(137 \mathrm{mg}, 2.18 \mathrm{mmol})$ was added to a solution of 21 (414 mg, $0.87 \mathrm{mmol})$ in DMF $(7.5 \mathrm{~mL})$. After heating at $70{ }^{\circ} \mathrm{C}$ for $3 \mathrm{~h}$, the solvent was evaporated and the residue diluted with $\mathrm{CH}_{2} \mathrm{Cl}_{2}$ and washed with water and brine. The organic phase was dried, filtered, and concentrated. Purification by chromatography column (AcOEt:cyclohexane 1:6) afforded 22 as an oil $(276 \mathrm{mg}, 92 \%) .[\alpha]_{\mathrm{D}}^{28}+60.4\left(c 0.55, \mathrm{CH}_{2} \mathrm{Cl}_{2}\right) . \mathrm{IR} v_{\max } 2986,2938,2103$ 
$\left(\mathrm{N}_{3}\right), 1693(\mathrm{C}=\mathrm{O}), 1403,1210,1026,697 \mathrm{~cm}^{-1} .{ }^{1} \mathrm{H}$ NMR (300 MHz, DMSO- $\left.d_{6}, 363 \mathrm{~K}, \delta \mathrm{ppm}\right) \delta$ 7.39-7.28 (m, 5H, H-arom.), 5.14 (d, $1 \mathrm{H},{ }^{2} J_{\mathrm{H}, \mathrm{H}} 12.5, \mathrm{CH}_{2}$ of Cbz), 5.08 (d, $1 \mathrm{H}, \mathrm{CH}_{2}$ of Cbz), 4.68 (t, $\left.1 \mathrm{H}, J_{4,3}=J_{4,5} 6.2, \mathrm{H}-4\right), 4.56\left(\mathrm{dd}, 1 \mathrm{H}, J_{3,2} 1.0, \mathrm{H}-3\right), 3.99$ (m, $\left.1 \mathrm{H}, \mathrm{H}-2\right), 3.90$ (q, $1 \mathrm{H}, J_{5, \mathrm{Me}} 6.4$,

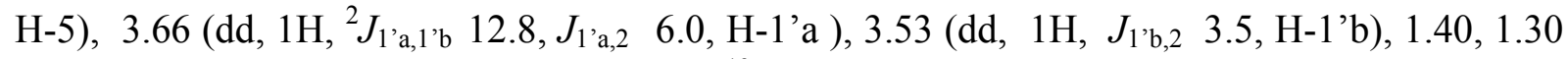
$\left(2 \mathrm{~s}, 3 \mathrm{H}\right.$ each, $\mathrm{C}\left(\mathrm{CH}_{3}\right)_{2}$, 1.29 (d, 3H, Me). ${ }^{13} \mathrm{C}$ NMR $\left(75.4 \mathrm{MHz}, \mathrm{DMSO}-d_{6}, 363 \mathrm{~K}, \delta \mathrm{ppm}\right) \delta$

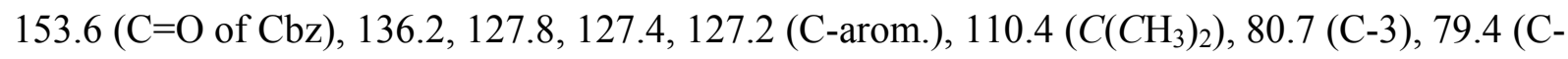

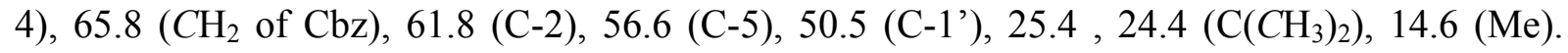
CIMS $m / z 347\left[2 \%,(\mathrm{M}+\mathrm{H})^{+}\right], 290\left[26 \%,\left(\mathrm{M}^{-} \mathrm{CH}_{2} \mathrm{~N}_{3}\right)^{+}\right]$. HRCIMS $m / z$ found 347.1727, calcd. for $\mathrm{C}_{17} \mathrm{H}_{23} \mathrm{~N}_{4} \mathrm{O}_{4}[\mathrm{M}+\mathrm{H}]^{+}: 347.1719$.

(2R,3R,4S)- $N$-Benzyloxycarbonyl-2-azidomethyl-3,4-O-isopropylidene-pyrrolidine-3,4-diol (25). A solution of $\mathrm{NaIO}_{4}(3.0 \mathrm{~g}, 14.0 \mathrm{mmol})$ in $\mathrm{H}_{2} \mathrm{O}(40 \mathrm{~mL})$ was added dropwise to a $0{ }^{\circ} \mathrm{C}$ solution of diol $23^{33}(2.36 \mathrm{~g}, 7.0 \mathrm{mmol})$ in THF (35 mL). After $45 \mathrm{~min}$., THF was evaporated and the mixture extracted with $\mathrm{CH}_{2} \mathrm{Cl}_{2}$. The organic phases were washed with water, sat. aq. soln. of $\mathrm{NaHCO}_{3}$ and brine, dried, filtered and concentrated. The aldehyde obtained was then dissolved in $\mathrm{MeOH}(40 \mathrm{~mL})$, cooled to $0{ }^{\circ} \mathrm{C}$ and $\mathrm{NaBH}_{4}(260 \mathrm{mg}, 6.8 \mathrm{mmol})$ was added. After $30 \mathrm{~min}$., the mixture was diluted with $\mathrm{CH}_{2} \mathrm{Cl}_{2}$, and washed with water and brine. The organic phase was dried, filtered and concentrated. The crude alcohol so-obtained was then dissolved in dry pyridine $(25 \mathrm{~mL}), \mathrm{TsCl}(4.34 \mathrm{~g}, 22.8 \mathrm{mmol})$ was added and the mixture stirred at $20{ }^{\circ} \mathrm{C}$ for $12 \mathrm{~h}$. Water was added dropwise under stirring and the mixture evaporated to dryness. The residue was dissolved in $\mathrm{CH}_{2} \mathrm{Cl}_{2}$ and washed with water and brine. The organic phase was dried, filtered and concentrated. The tosylate ester $\mathbf{2 4}^{32}$ so-obtained was dissolved in DMF (30 mL) and $\mathrm{NaN}_{3}(0.93$ g, $14.2 \mathrm{mmol}$ ) was added. After heating to $50{ }^{\circ} \mathrm{C}$ for $2.5 \mathrm{~h}$, the solvent was evaporated and the residue diluted with $\mathrm{CH}_{2} \mathrm{Cl}_{2}$ and washed with water and brine. The organic phase was dried, filtered, and concentrated. Purification by chromatography column (AcOEt:cyclohexane 1:1) afforded 25 (1.68 g, $72 \%, 4$ steps). $[\alpha]_{\mathrm{D}}^{27}=-46.0\left(c 0.87, \mathrm{CH}_{2} \mathrm{Cl}_{2}\right)$. IR $v_{\max } 2996,2938,2103$ $\left(\mathrm{N}_{3}\right), 1698(\mathrm{C}=\mathrm{O}), 1350,1043,769 \mathrm{~cm}^{-1} .{ }^{1} \mathrm{H}$ NMR (300 MHz, DMSO-d $\left.6,363 \mathrm{~K}\right) \delta 7.33-7.29$

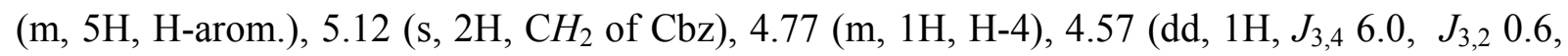
H-3), 4.07 (br. t, $1 \mathrm{H}, J_{2,1}$ 'a 5.7 , H-2), 3.74 (dd, $\left.1 \mathrm{H}, J_{5 \mathrm{a}, 4} 1.2,{ }^{2} J_{5 \mathrm{a}, 5 \mathrm{~b}} 12.9, \mathrm{H}-5 \mathrm{a}\right), 3.56-3.44$ (m, 3H, $\mathrm{H}-5 \mathrm{~b}, \mathrm{H}-1$ 'a, H-1'b), 1.32, 1.26 (2s, 3H each, C(CH $\left.\mathrm{CH}_{2}\right) .{ }^{13} \mathrm{C}$ NMR $\left(75.4 \mathrm{MHz}, \mathrm{DMSO}-d_{6}, 363 \mathrm{~K}\right)$

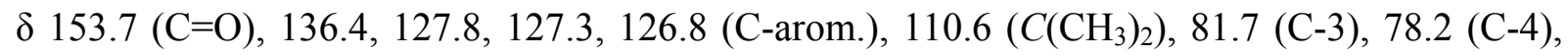
$65.9\left(\mathrm{CH}_{2}\right.$ of $\left.\mathrm{Cbz}\right), 62.6(\mathrm{C}-2), 51.4(\mathrm{C}-5), 50.3\left(\mathrm{C}-1^{\prime}\right), 26.3\left(\mathrm{C}\left(\mathrm{CH}_{3}\right)_{2}\right), 24.4\left(\mathrm{C}_{\left.\left(\mathrm{CH}_{3}\right)_{2}\right)}\right)$ HRCIMS: calculated for $\mathrm{C}_{16} \mathrm{H}_{21} \mathrm{~N}_{4} \mathrm{O}_{4}: 333.1563$, found $333.1570[\mathrm{M}+\mathrm{H}]^{+}$.

\section{(2R,3S,4R)- $N$-Benzyloxycarbonyl-2-azidoethyl-3,4-O-isopropylidene-pyrrolidine-3,4-diol}

(28). $\mathrm{NaHCO}_{3}(155 \mathrm{mg}, 1.84 \mathrm{mmol})$ and $\mathrm{CbzCl}(310 \mu \mathrm{L}, 2.02 \mathrm{mmol})$ were added to a solution of $26^{34}$ (421.7 mg, $1.84 \mathrm{mmol}$ ) in EtOH: $\mathrm{H}_{2} \mathrm{O}(1: 1,10 \mathrm{~mL})$, and the mixture stirred at r.t for $3 \mathrm{~h}$. Then, it was poured into a sat. aq. soln. of $\mathrm{NaHCO}_{3}$ and extracted with $\mathrm{AcOEt}$. The dried organic phase was evaporated and the obtained residue was purified by column chromatography over silica gel (AcOEt:cyclohexane, 1:3) affording the corresponding $N$-protected pyrrolidine (594.9 $\mathrm{mg}, 97 \%)$. Then, to a cooled $\left(-10^{\circ} \mathrm{C}\right)$ suspension of $\mathrm{LiAlH}_{4}(35 \mathrm{mg}, 0.91 \mathrm{mmol})$ in anh. THF (3 $\mathrm{mL})$, the protected pyrrolidine $(274 \mathrm{mg}, 0.756 \mathrm{mmol})$ in THF $(5 \mathrm{~mL})$ was added. After $10 \mathrm{~min}$., 
sat. aq. soln. of $\mathrm{Na}_{2} \mathrm{SO}_{4}(20 \mathrm{~mL})$ was added dropwise and the mixture extracted with AcOEt. The dried organic phase was evaporated and the obtained residue was purified by column chromatography over silica gel (toluene:acetone, 5:1) to afford the corresponding hydroxyethyl pyrrolidine $27(171 \mathrm{mg}, 70 \%)$. To a solution of this compound (221 $\mathrm{mg}, 0.69 \mathrm{mmol})$ in anh. $\mathrm{CH}_{2} \mathrm{Cl}_{2}(4 \mathrm{~mL})$, anh. pyridine $(3 \mathrm{~mL})$ and $\mathrm{MsCl}(160 \mu \mathrm{L}, 2.06 \mathrm{mmol})$ were added. After $1.5 \mathrm{~h}$, the reaction was quenched with water $(4 \mathrm{~mL})$ and evaporated. The residue was diluted with $\mathrm{CH}_{2} \mathrm{Cl}_{2}$, washed with water and brine, dried, filtered and concentrated. The crude product was then dissolved in anh. DMF $(5 \mathrm{~mL})$ and $\mathrm{NaN}_{3}(135 \mathrm{mg}, 2.06 \mathrm{mmol})$ was then added. The mixture was heated at $70{ }^{\circ} \mathrm{C}$ for $3 \mathrm{~h}$ and then evaporated. The residue was dissolved in $\mathrm{CH}_{2} \mathrm{Cl}_{2}$, washed with water and brine, dried, filtered and concentrated. The resulting residue was purified by column chromatography (AcOEt:cyclohexane 1:4) to give pure 28 as an oil (144.8 $\mathrm{mg}, 61 \%, 2$ steps). $[\alpha]_{\mathrm{D}}^{28}-53.6\left(c 1.04, \mathrm{CH}_{2} \mathrm{Cl}_{2}\right)$; IR $\left(v \mathrm{~cm}^{-1}\right)$ 2981, 2937, $2093\left(\mathrm{~N}_{3}\right), 1700(\mathrm{C}=\mathrm{O}), 1410,1206$, 1084, 747. ${ }^{1} \mathrm{H}-\mathrm{NMR}\left(300 \mathrm{MHz}, \mathrm{DMSO}-d_{6}, 363 \mathrm{~K}, \delta \mathrm{ppm}, J \mathrm{~Hz}\right) 7.37-7.30$ (m, 5H, H-arom.), 5.01 (s, 2H, $\mathrm{CH}_{2}$ of Cbz), 4.79-4.72 (m, 2H, H-4, H-3), 3.96-3.81 (m, 1H, H-2), 3.79-3.73 (m, 1H, H-5a), 3.41-3.28 (m, 3H, H-2', H-5b), 2.16-2.05 (m, 1H, H-1'a), 2.01-1.92 (m, 1H, H-1'b), $1.44,1.30\left(2 \mathrm{~s}, 3 \mathrm{H}\right.$ each, $\left.-\mathrm{C}\left(\mathrm{CH}_{3}\right)_{2}\right) .{ }^{13} \mathrm{C}-\mathrm{NMR}\left(75.4 \mathrm{MHz}, \mathrm{DMSO}-d_{6}, 363 \mathrm{~K}, \delta \mathrm{ppm}\right) 154.2$ $(\mathrm{C}=\mathrm{O}), 136.5,128.0,127.4,127.1$ (C-arom.), $111.5\left(-\mathrm{C}\left(\mathrm{CH}_{3}\right)_{2}\right), 79.2,77.0(\mathrm{C}-3, \mathrm{C}-4), 65.9\left(\mathrm{CH}_{2}\right.$ of Cbz), 57.2 (C-2), 50.4 (C-5), 48.0 (C-2'), $28.0\left(\mathrm{C}-1\right.$ '), $25.9\left(-\mathrm{C}\left(\mathrm{CH}_{3}\right)_{2}\right), 24.6\left(-\mathrm{C}\left(\mathrm{CH}_{3}\right)_{2}\right)$. CIMS $m / z 347\left[11 \%,(\mathrm{M}+\mathrm{H})^{+}\right]$. HRCIMS $m / z$ found 347.1712 , calc. for $\mathrm{C}_{17} \mathrm{H}_{23} \mathrm{~N}_{4} \mathrm{O}_{4}: 347.1719$. (2S,3S,4R,5S)-2-[(4'’-Dodecyl)-1H-1,2,3-triazole-1-yl)methyl)]-5-methylpyrrolidine-3,4-diol hydrochloride (31). Tetradec-1-yne ( $43 \mu \mathrm{L}, 0.21 \mathrm{mmol})$, DIPEA (41 $\mu \mathrm{L}, 0.42 \mathrm{mmol})$ and CuI (7 $\mathrm{mg}, 0.03 \mathrm{mmol})$ were added to a solution of $22(39.6 \mathrm{mg}, 0.114 \mathrm{mmol})$ in toluene $(1 \mathrm{~mL})$. The mixture was stirred at r.t. for $20 \mathrm{~h}$ and then, a sat. aq. soln. of $\mathrm{NaHCO}_{3}$ was added and extracted with AcOEt. The organic phases were dried, filtered and concentrated. Purification by chromatography column $\left(\mathrm{Et}_{2} \mathrm{O}\right.$ :cyclohexane $\left.2: 1\right)$ afforded the triazole derivative $(58.3 \mathrm{mg}, 95 \%)$. $[\alpha]_{\mathrm{D}}^{27}+80.1\left(c 0.96, \mathrm{CH}_{2} \mathrm{Cl}_{2}\right) . \mathrm{IR} v_{\max } 2918,2849,1726(\mathrm{C}=\mathrm{O}), 1201,1027,738 \mathrm{~cm}^{-1} .{ }^{1} \mathrm{H} \mathrm{NMR}$ (300 MHz, DMSO- $d_{6}, 363 \mathrm{~K}, \delta$ ppm) $\delta 7.54$ (s, 1H, H-5' '), 7.41-7.32 (m, 5H, H-arom.), 5.13 (d, $1 \mathrm{H},{ }^{2} J_{\mathrm{H}, \mathrm{H}} 12.3, \mathrm{CH}_{2}$ of $\left.\mathrm{Cbz}\right), 5.07\left(\mathrm{~d}, 1 \mathrm{H}, \mathrm{CH}_{2}\right.$ of Cbz), $4.74\left(\mathrm{~d}, 1 \mathrm{H}, J_{3,4} 6.0, \mathrm{H}-3\right), 4.62(\mathrm{dd}, 1 \mathrm{H}$,

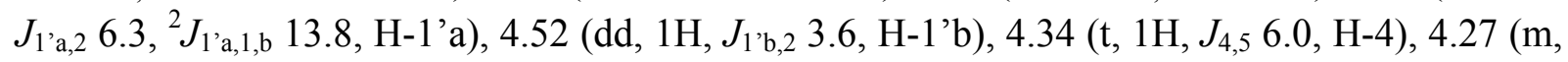
$1 \mathrm{H}, \mathrm{H}-2), 3.38$ (q, $\left.1 \mathrm{H}, J_{5, \mathrm{Me}} 6.0, \mathrm{H}-5\right), 2.60\left(\mathrm{t}, 2 \mathrm{H}, J_{\mathrm{H}, \mathrm{H}} 7.5,-\mathrm{CH}_{2}\left(\mathrm{CH}_{2}\right)_{10} \mathrm{CH}_{3}\right), 1.58\left(\mathrm{q}, 2 \mathrm{H}, J_{\mathrm{H}, \mathrm{H}}\right.$ 6.3, $\left.-\mathrm{CH}_{2} \mathrm{CH}_{2}\left(\mathrm{CH}_{2}\right)_{9} \mathrm{CH}_{3}\right), 1.37-1.23\left(\mathrm{~m}, 27 \mathrm{H},-\mathrm{CH}_{2} \mathrm{CH}_{2}\left(\mathrm{CH}_{2}\right)_{9} \mathrm{CH}_{3},-\mathrm{C}\left(\mathrm{CH}_{3}\right)_{2}, \mathrm{Me}\right), 0.87$ (t, 3H, $\left.J_{\mathrm{H}, \mathrm{H}} 7.2,-\left(\mathrm{CH}_{2}\right)_{11} \mathrm{CH}_{3}\right) .{ }^{13} \mathrm{C} \mathrm{NMR}\left(75.4 \mathrm{MHz}, \mathrm{DMSO}-d_{6}, 363 \mathrm{~K}, \delta \mathrm{ppm}\right) \delta 153.6(\mathrm{C}=\mathrm{O}), 146.8$ (C-4"'), 136.2, 127.8, 127.4, 127.3 (C-arom.), 122.0 (C-5'), $110.3\left(C\left(\mathrm{CH}_{3}\right)_{2}\right), 80.2$ (C-4), 79.4 (C-3), $65.8\left(\mathrm{CH}_{2}\right.$ of Cbz), 62.4 (C-2), 56.3 (C-5), 48.4 (C-1'), 30.7, 28.4, 28.3, 28.2, 28.1, 27.9, 25.3, 24.4, 21.4, $14.4\left(11-\mathrm{CH}_{2},-\mathrm{C}\left(\mathrm{CH}_{3}\right)_{2}, \mathrm{Me}\right), 13.2\left(-\left(\mathrm{CH}_{2}\right)_{11} \mathrm{CH}_{3}\right)$. LSIMS $m / z 563[52 \%$, $(\mathrm{M}+\mathrm{Na})^{+}$]. HRLSIMS $\mathrm{m} / z$ found 563.3564, calc. for $\mathrm{C}_{31} \mathrm{H}_{48} \mathrm{~N}_{4} \mathrm{O}_{4} \mathrm{Na}$ : 563.3573. Deprotection of this compound $(49.5 \mathrm{mg}, 0.092 \mathrm{mmol})$ was carried out in $\mathrm{HCl}(1 \mathrm{M})$ :THF 1:1 $(5 \mathrm{~mL})$ at r.t overnight. Solvent was then evaporated and the residue was purified by chromatography column over silica gel $\left(\mathrm{CH}_{2} \mathrm{Cl}_{2}: \mathrm{MeOH}, 20: 1\right)$ affording the corresponding 3,4-O-unprotected derivative (47.6 mg, 95\%). To a solution of this derivative (43.6 mg, $0.087 \mathrm{mmol})$ in $\mathrm{MeOH}(2 \mathrm{~mL}), \mathrm{Pd} / \mathrm{C}$ 
$(10 \%)$ and $\mathrm{HCl}(5 \mathrm{M}, 70 \mu \mathrm{L})$ were added. The mixture was hydrogenated at 1 atm for $3 \mathrm{~h}$ and then diluted with $\mathrm{MeOH}$, filtered through Celite, and evaporated, to afford $\mathbf{3 1}$ as an amorphous solid (33.2 mg, 95\%). $[\alpha]_{\mathrm{D}}^{27}-16.5(c 0.95, \mathrm{MeOH})$. IR $v_{\max } 3374(\mathrm{OH}, \mathrm{NH}), 2920,2851,1636$, $1120 \mathrm{~cm}^{-1} .{ }^{1} \mathrm{H}$ NMR (300 MHz, MeOD, $\delta$ ppm) $\delta 8.38$ (s, 1H, H-5' '), 5.10-4.90 (m, 2H, H-1'a, H-1 'b), 4.29-4.07 (m, 3H, H-2, H-3, H-4), 3.88 (m, 1H, H-5), 2.84 (br s, $2 \mathrm{H},-\mathrm{CH}_{2}\left(\mathrm{CH}_{2}\right)_{11} \mathrm{CH}_{3}$ ), 1.74 (br s, $\left.2 \mathrm{H},-\mathrm{CH}_{2} \mathrm{CH}_{2}\left(\mathrm{CH}_{2}\right)_{9} \mathrm{CH}_{3}\right), 1.41-1.29\left(\mathrm{~m}, 23 \mathrm{H}, \mathrm{CH}_{2}\left(\mathrm{CH}_{2}\right){ }_{10} \mathrm{CH}_{3}, \mathrm{Me}\right), 0.89$ (t, 3H, $J_{\mathrm{H}, \mathrm{H}}$ 6.6, - $\left.\left(\mathrm{CH}_{2}\right)_{11} \mathrm{CH}_{3}\right) .{ }^{13} \mathrm{C}$ NMR (75.4 MHz, MeOD, $\delta$ ppm) $\delta 148.5$ (C-4'), 126.5 (C-5'), 75.4, 72.6, 61.2 (C-2, C-3, C-4), 59.2 (C-5), 51.8 (C-1'), 33.0, 30.7, 30.6, 30.4, 30.3, 30.1, 30.0, 25.5, $23.6\left(11 \mathrm{CH}_{2}\right), 14.4\left(-\left(\mathrm{CH}_{2}\right)_{11} \mathrm{CH}_{3}\right), 12.1(\mathrm{Me})$. LSIMS $\mathrm{m} / z 367\left[62 \%,(\mathrm{M}+\mathrm{H})^{+}\right]$. HRLSIMS $\mathrm{m} / \mathrm{z}$ found 367.3056, calc. for $\mathrm{C}_{20} \mathrm{H}_{39} \mathrm{~N}_{4} \mathrm{O}_{2}$ : 367.3073 .

\section{(2R,3R,4S)-2-[(4’'-dodecyl)-1H-1,2,3-triazole-1-yl)methyl)-pyrrolidine-3,4-diol}

hydrochloride (32). To a solution of $25(75 \mathrm{mg}, 0.23 \mathrm{mmol})$ in toluene $(2 \mathrm{~mL})$ were added tetradec-1-yne $(72 \mu \mathrm{L}, 0.30 \mathrm{mmol})$, DIPEA $(85.1 \mu \mathrm{L}, 0.83 \mathrm{mmol})$ and $\mathrm{CuI}(13 \mathrm{mg}, 0.07 \mathrm{mmol})$. The mixture was stirred at r.t. for $20 \mathrm{~h}$ and then, a sat. aq. soln. of $\mathrm{NaHCO}_{3}$ was added and extracted with AcOEt. The organic phases were dried, filtered and concentrated. Purification by chromatography column (AcOEt:cyclohexane 1:2) afforded the corresponding triazole derivative (95 mg, 80\%). $[\alpha]_{\mathrm{D}}^{27}-58.6\left(c 0.81, \mathrm{CH}_{2} \mathrm{Cl}_{2}\right)$. IR $v_{\max } 2917,2848,1692(\mathrm{C}=\mathrm{O}), 1425,1053,700$ $\mathrm{cm}^{-1} .{ }^{1} \mathrm{H}$ NMR (300 MHz, DMSO- $\left.d_{6}, 363 \mathrm{~K}, \delta \mathrm{ppm}\right) \delta 7.66$ (s, 1H, H-5') $)$ 7.37-7.28 (m, 5H, Harom.), $5.11\left(\mathrm{~d}, 1 \mathrm{H},{ }^{2} J_{\mathrm{H}, \mathrm{H}} 12.9, \mathrm{CH}_{2}\right.$ of Cbz), $5.01\left(\mathrm{~d}, 1 \mathrm{H}, \mathrm{CH}_{2}\right.$ of Cbz), $4.72\left(\mathrm{~d}, 1 \mathrm{H}, J_{3,4} 5.7, \mathrm{H}-\right.$ 3), 4.59 (dd, $\left.1 \mathrm{H}, J_{4,5} 10.8, \mathrm{H}-4\right), 4.54$ (dd, $1 \mathrm{H},{ }^{2} J_{1^{\prime} \mathrm{a}, 1^{\prime} \mathrm{b}} 14.1, J_{1 \mathrm{a}^{\prime}, 2} 6.6, \mathrm{H}-1$ 'a), 4.45 (dd, $1 \mathrm{H}, J_{1^{\prime} \mathrm{b}, 2}$ 5.7, H-1 'b), 4.35 (t, 1H, $\left.J_{2,5} 6.0, \mathrm{H}-2\right), 3.67$ (d, 1H, $\left.{ }^{2} J_{5 \mathrm{a}, 5 \mathrm{~b}} 12.8, \mathrm{H}-5 \mathrm{a}\right), 3.10$ (dd, 1H, H-5b), 2.60 $\left(\mathrm{t}, 2 \mathrm{H}, J_{\mathrm{H}, \mathrm{H}} 7.4,-\mathrm{CH}_{2}\left(\mathrm{CH}_{2}\right)_{10} \mathrm{CH}_{3}\right), 1.59\left(\mathrm{q}, 2 \mathrm{H}, J_{\mathrm{H}, \mathrm{H}} 7.3,-\mathrm{CH}_{2} \mathrm{CH}_{2}\left(\mathrm{CH}_{2}\right)_{9} \mathrm{CH}_{3}\right), 1.30-1.25$ (m, $\left.24 \mathrm{H},-\mathrm{CH}_{2} \mathrm{CH}_{2}\left(\mathrm{CH}_{2}\right)_{9} \mathrm{CH}_{3},-\mathrm{C}\left(\mathrm{CH}_{3}\right)_{2}\right), 0.87\left(\mathrm{t}, 3 \mathrm{H},{ }^{2} \mathrm{~J}_{\mathrm{H}, \mathrm{H}} 6.6,-\left(\mathrm{CH}_{2}\right)_{11} \mathrm{CH}_{3}\right) .{ }^{13} \mathrm{C} \mathrm{NMR} \quad(75.4$ $\left.\mathrm{MHz}, \mathrm{DMSO}-d_{6}, 363 \mathrm{~K}, \delta \mathrm{ppm}\right) \delta 153.7(\mathrm{C}=\mathrm{O}), 146.8\left(\mathrm{C}-4{ }^{\prime}\right), 136.4,127.8,127.2,126.7(\mathrm{C}-$

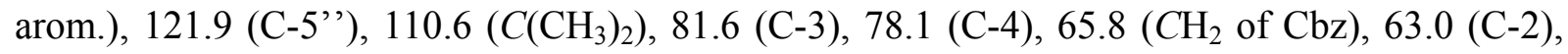
51.0 (C-5), 48.3 (C-1'), 30.7, 28.4, 28.2, 28.0, 27.9, 26.2, 24.4, 24.3, $21.4\left(10 \mathrm{CH}_{2},-\mathrm{C}\left(\mathrm{CH}_{3}\right)_{2}\right)$, $13.2\left(-\left(\mathrm{CH}_{2}\right)_{11} \mathrm{CH}_{3}\right)$. HRLSIMS calculated for $\mathrm{C}_{30} \mathrm{H}_{46} \mathrm{~N}_{4} \mathrm{O}_{4} \mathrm{Na}$ : 549.3417, found 549.3409 $[\mathrm{M}+\mathrm{Na}]^{+}$. Deprotection of this compound $(80.5 \mathrm{mg}, 0.149 \mathrm{mmol})$ as indicated for the preparation of 31 afforded 32 as an amorphous solid $(44.4 \mathrm{mg}, 92 \%)$. $[\alpha]_{\mathrm{D}}^{27}+22.9(c 0.96, \mathrm{MeOH})$. IR $v_{\max }$ $3382,3240(\mathrm{OH}, \mathrm{NH}), 2921,2851,1638,1136 \mathrm{~cm}^{-1} .{ }^{1} \mathrm{H}$ NMR $\left(300 \mathrm{MHz}, \mathrm{DMSO}-d_{6}, \delta \mathrm{ppm}\right) \delta$ 10.03 (br s, 1H, NH), 9.80 (br s, 1H, NH), 8.13 (s, 1H, H-5'), 4.97 (dd, 1H, ${ }^{2} J_{1}$ 'a, 1'b 14.3, H-1'a), 4.74 (m, 1H, H-1'b), 4.11 (m, 1H, H-4), 3.91 (m, 1H, H-3), 3.67 (m, 1H, H-2), 3.38 (m, 1H, H5a), $3.01(\mathrm{~m}, 1 \mathrm{H}, \mathrm{H}-5 \mathrm{~b}), 2.59$ (br t, $\left.2 \mathrm{H},{ }^{2} J_{\mathrm{H}, \mathrm{H}} 6.99,-\mathrm{CH}_{2}\left(\mathrm{CH}_{2}\right)_{10} \mathrm{CH}_{3}\right), 1.57(\mathrm{~m}, 2 \mathrm{H}$, $\left.\mathrm{CH}_{2} \mathrm{CH}_{2}\left(\mathrm{CH}_{2}\right)_{9} \mathrm{CH}_{3}\right), 1.23\left(\mathrm{~m}, 18 \mathrm{H},-\mathrm{CH}_{2} \mathrm{CH}_{2}\left(\mathrm{CH}_{2}\right)_{9} \mathrm{CH}_{3}\right), 0.84\left(\mathrm{~m}, 3 \mathrm{H},-\left(\mathrm{CH}_{2}\right)_{11} \mathrm{CH}_{3} .{ }^{13} \mathrm{C} \mathrm{NMR}\right.$ (75.4 MHz, DMSO- $d_{6}, 363 \mathrm{~K}, \delta$ ppm) $\delta 146.8$ (C-4' '), 122.8 (C-5'”), 73.0 (C-3), 68.3 (C-4), 59.6 (C-2), 49.3 (C-5), 48.2 (C-1'), 31.2, 29.0, 28.9, 28.8, 28.7, 28.6, 28.5, 24.9, $22.0\left(11 \mathrm{CH}_{2}\right), 13.9$ $\left(-\left(\mathrm{CH}_{2}\right)_{11} \mathrm{CH}_{3}\right)$. LSIMS $\mathrm{m} / z 353\left[80 \%,(\mathrm{M}+\mathrm{H})^{+}\right], 375\left[100 \%,(\mathrm{M}+\mathrm{Na})^{+}\right]$. HRLSIMS calculated for $\mathrm{C}_{19} \mathrm{H}_{37} \mathrm{~N}_{4} \mathrm{O}_{2}$ : 353.2917, found $353.2929[\mathrm{M}+\mathrm{H}]^{+}$. 
(2R,3S,4R)-2-[(4'’-Dodecyl)-1H-1,2,3-triazole-1-yl)ethyl)-pyrrolidine-3,4-diol hydrochloride (33). Tetradec-1-yne (47 $\mu \mathrm{L}, 0.19 \mathrm{mmol})$, DIPEA $(110 \mu \mathrm{L}, 0.64 \mathrm{mmol})$ and CuI (11 mg, 0.06 mmol) were added to a solution of $28(60 \mathrm{mg}, 0.173 \mathrm{mmol})$ in toluene $(1.5 \mathrm{~mL})$. The mixture was stirred at r.t. for $24 \mathrm{~h}$ and then, a sat. aq. soln. of $\mathrm{NaHCO}_{3}$ was added and extracted with AcOEt. The organic phases were dried, filtered and concentrated. Purification by chromatography column (AcOEt:cyclohexane 1:2) afforded the triazole derivative (76 mg, 81\%). Deprotection of this compound $(60 \mathrm{mg}, 0.111 \mathrm{mmol})$ as indicated for the preparation of 31 afforded 33 as an amorphous solid (81\%, 2 steps). $[\alpha]_{\mathrm{D}}^{26}-8.3(c 0.73, \mathrm{MeOH})$; IR $\left(v \mathrm{~cm}^{-1}\right) 3362$ (OH), 2923, 2852, 1636, 1126, 1048. ' H-NMR (300 MHz, MeOD, $\delta$ ppm) $\delta 8.34$ (s, 1H, H-5' '), $4.72(\mathrm{~m}, 2 \mathrm{H}), 4.43(\mathrm{~m}, 1 \mathrm{H}), 4.19(\mathrm{~m}, 1 \mathrm{H}), 3.64(\mathrm{~m}, 1 \mathrm{H}), 3.44(\mathrm{~m}, 1 \mathrm{H}), 3.15(\mathrm{~m}, 1 \mathrm{H}), 2.84(\mathrm{~m}$, $2 \mathrm{H}), 2.63-2.46\left(\mathrm{~m}, 2 \mathrm{H},-\mathrm{CH}_{2}\left(\mathrm{CH}_{2}\right)_{11} \mathrm{CH}_{3}\right), 1.75$ (br s, $\left.2 \mathrm{H},-\mathrm{CH}_{2} \mathrm{CH}_{2}\left(\mathrm{CH}_{2}\right)_{9} \mathrm{CH}_{3}\right), 1.34(\mathrm{~m}, 18 \mathrm{H},-$ $\left.\mathrm{CH}_{2} \mathrm{CH}_{2}\left(\mathrm{CH}_{2}\right)_{9} \mathrm{CH}_{3}\right), 0.89$ (t, 3H, $\left.J_{\mathrm{H}, \mathrm{H}} 5.9,-\left(\mathrm{CH}_{2}\right)_{11} \mathrm{CH}_{3}\right) .{ }^{13} \mathrm{C}-\mathrm{NMR}(75.4 \mathrm{MHz}, \mathrm{MeOD}, \delta \mathrm{ppm})$ 146.6 (C-4'), 128.7 (C-5'), 72.0, 71.6, 60.7, 51.4, 32.9, 30.6, 30.6, 30.5, 30.3, 30.2, 29.6, 28.3, 25.1, 23.6, $14.3\left(-\left(\mathrm{CH}_{2}\right)_{11} \mathrm{CH}_{3}\right)$. CIMS $m / z 367\left[100 \%\right.$, $\left.(\mathrm{M}+\mathrm{H})^{+}\right]$. HRCIMS $m / z$ found 367.3071 , calc. for $\mathrm{C}_{20} \mathrm{H}_{39} \mathrm{~N}_{4} \mathrm{O}_{2}: 367.3073$.

Cell lines and culture conditions. MiaPaCa2 and PK9 pancreatic ductal adenocarcinoma cells were obtained from American Type Culture Collection (ATCC, Rockville, MD, U.S.A.). Cells were cultured in RPMI (Gibco, Paisley, United Kingdom) supplemented with $10 \%$ heat inactivated fetal calf serum (FCS; Amimed, BioConcept, Allschwil, Switzerland) and 1\% penicillin/streptomycin at $37^{\circ} \mathrm{C}$ (BioConcept) in a humidified atmosphere of $95 \%$ air and $5 \%$ $\mathrm{CO}_{2}$.

Colorimetric cell growth assays. $5 \times 10^{3} \mathrm{MiaPaCa} 2$ or PK9 cells/well were plated in 96-well plates and allowed to adhere overnight. Thereafter, cells were incubated with or without compounds in a final volume of $200 \mu \mathrm{L}$ medium for $72 \mathrm{~h}$. Subsequently, cell viability was measured with CellTiter96 Aqueous1 (Promega) according to the manufacturer's instructions. Means of triplicate wells were analyzed. $\mathrm{IC}_{50} \mathrm{~s}$ were estimated using GraphPad Sofware (GraphPad, La Jolla, CA, USA).

\section{Acknowledgements}

This work was supported by the European Community's Seventh Framework Programme FP7 (grant HEALTH-F2-2010-256986, PANACREAS), the Associzione Italiana per la ricerca sul cancro (AICR START-UP grant \#6108 to A.N.), Ministerio de Economía y Competitividad of Spain (CTQ2012-31247) and Junta de Andalucía (FQM 345). P.E.R. thanks the Ministerio de Educación of Spain for a FPU fellowship and S. J. C. thanks the Fundación Cámara for a grant. The authors thank M. Sánchez Mora for technical assistance. 


\section{References}

1. Sato, S.; Kuramoto, M.; Ono, N. Tetrahedron Lett. 2006, 47, 7871.

http://dx.doi.org/10.1016/j.tetlet.2006.09.020

2. Biersack, B.; Diestel, R.; Jagusch, C.; Rapp, G.; Sasse, F.; Schobert, R. Chem. Biodiversity 2008, 5, 2423.

http://dx.doi.org/10.1002/cbdv.200890207

PMid:19035571

3. Deniau, A.-L.; Mosset, P.; Le Bot, D.; Legrand, A. B. Biochimie 2011, 93, 1.

http://dx.doi.org/10.1016/j.biochi.2009.12.010

PMid:20036307

4. Loh, K. T.; Roskelley, C. D.; Andersen, R. J.; O’Connor, T. P. Neuroscience 2006, 139, 1263.

http://dx.doi.org/10.1016/j.neuroscience.2006.01.065

PMid:16564636

5. Alam, N.; Wang, W.; Hong, J.; Lee, C.-O.; Im, K. S.; Jung, J. H. J. Nat. Prod. 2002, 65, 944. http://dx.doi.org/10.1021/np010312v

6. Pettit, G. R.; Tang, Y.; Knight, J. C. J. Nat. Prod. 2005, 68, 974 .

http://dx.doi.org/10.1021/np040107q

PMid:16038534 PMCid:PMC3275634

7. Gajate, C.; Matos-da-Silva, M.; Dakir, E. L-H.; Fonteriz, R. I.; Alvarez, J.; Mollinedo, F. Oncogene 2012, 31, 2627.

http://dx.doi.org/10.1038/onc.2011.446

PMid:22056873

8. Gajate, C.; Mollinedo, F. Recent Patents on Anti-Cancer Drug Discovery 2011, 6, 274.

http://dx.doi.org/10.2174/157489211796957766

PMid:21762074

9. Mollinedo, F.; de la Iglesia-Vicente, J.; Gajate, C.; de Mendoza, A. E.-H.; Villa-Pulgarin, J. A.; de Frias, M.; Roue, G.; Gil, J.; Colomer, D.; Campanero, M. A. Clin. Cancer Res., 2010, 16, 2046.

http://dx.doi.org/10.1158/1078-0432.CCR-09-2456

PMid:20233887

10. Yang, D.; Torres, C. M.; Bardhan, K.; Zimmerman, M.; McGaha, T. L.; Liu, K. J. Immunol. 2012, 188, 4441.

11. Canals, D.; Mormeneo, D.; Fabrias, G.; Llebaria, A.; Casas, J.; Delgado, A. Bioorg. Med. Chem. 2009, 17, 235.

http://dx.doi.org/10.1016/j.bmc.2008.11.026

PMid:19056278

12. Li, K.; Ichikawa S.; Al-Dabbagh, B.; Bouhss, A.; Matsuda, A. J. Med. Chem. 2010, 53, 3793. 
http://dx.doi.org/10.1021/jm100243n

PMid:20405928

13. Zhang. Z.; Zong, C.; Song, G.; Lv, G.; Chun, Y.; Wang, P.; Ding, N.; Li, Y. Carbohydr. Res. 2010, 345, 750 .

http://dx.doi.org/10.1016/j.carres.2010.01.015

PMid:20170905

14. Vogel, J.; Bendas, G.; Bakowsky, U.; Hummel, G.; Schimdt, R. R.; Ketmann, U.; Rothe, U. Biochim Biophys Acta 1998, 1372, 205.

http://dx.doi.org/10.1016/S0005-2736(98)00058-3

15. Falconer R. A.; Toth, I. Bioorg Med Chem. 2007, 15, 7012.

http://dx.doi.org/10.1016/j.bmc.2007.07.048

PMid:17851079

16. Garcia-Alvarez, I.; Groult, H.; Casas, J.; Barreda-Manso, M. A.; Yanguas-Casas, N.; NietoSampedro, M.; Romero-Ramirez, L.; Fernandez-Mayoralas, A. J. Med. Chem. 2011, 54, 6949.

http://dx.doi.org/10.1021/jm200961q

PMid:21866909

17. Nieto-Sampedro, M.; Valle-Argos, B.; Gomez-Nicola, D.; Fernandez-Mayoralas, A.; NietoDiaz, M. Clin. Med. Insights Oncology 2011, 5, 265.

http://dx.doi.org/10.4137/CMO.S7685

PMid:22084619 PMCid:PMC3201112

18. Hai-Lin, Z.; Xiao-Peng, He.;'Li, S.; Yuan, Y.; Wei, Z.; Xiao-Xin, S.; Jia, L.; Guo-Rong, C. Mol. Divers 2011, 15, 889.

19. Mrestani, Y.; Härtl, A.; Neubert, R. H. H. Int. J. Pharm. 2006, 309, 67.

http://dx.doi.org/10.1016/j.ijpharm.2005.11.017

PMid:16377108

20. Mehta, A.; Zitzmann, N.; Rudd, P. M.; Block, T. M.; Dwek, R. A. FEBS Lett. 1998, 430, 17. http://dx.doi.org/10.1016/S0014-5793(98)00525-0

21. Godin, G.; Compain, P.; Martin, O. R.; Ikeda, K.; Yu, L.; Asano, N. Bioorg. Med. Chem. Lett. 2004, 14, 5991.

http://dx.doi.org/10.1016/j.bmcl.2004.09.086

PMid:15546715

22. Padró, M.; Castillo, J. A.; Gómez, L.; Joglar, J.; Clapés, P.; Bolós, C. Glycoconj. J. 2010, 27, 277.

http://dx.doi.org/10.1007/s10719-009-9276-3

PMid:20041292

23. Storer, R.; Tinsley, J. M.; Wilson, F. X.; Horne, G.; Wren, S. P.; Dorgan, C. R.; Van Well, R. M.; Fowler, L.; Czemerys, L. (2012): Pyrrolidine derivatives as selective glycosidase inhibitors and uses thereof PTC Int. Appl. WO 2012117219, A1 20120907.

24. Saotome, C; Wong, C.-H.; Kanie, O. Chem. Biol. 2001, 8, 1061. 
http://dx.doi.org/10.1016/S1074-5521(01)00074-6

25. Kanie, O.; Saotome, C. (2007): Preparation of aza-sugar compounds as specific inhibitors against sugar chain related enzymes US 7288565 B2 20071030.

26. Bello, C.; Vogel, P. (2009): Novel Dihydroxypyrrolidine Derivatives as Anti-Cancer Agents PTC Int. Appl. WO2009118712, A2 20091001.

27. Bello, C.; Dal Bello, G.; Cea, M.; Nahimana, A.; Aubry, D.; Garuti, A.; Motta, G.; Moran, E.; Fruscione, F.; Pronzato, P.; Grossi, F.; Patrone, F.; Ballestrero, A.; Dupuis, M.; Sordat, B.; Zimmermann, K.; Loretan, J.; Wartmann, M.; Duchosal, M. A.; Nencioni, A.; Vogel, P. Bioorg. Med. Chem. 2011, 19, 7720.

http://dx.doi.org/10.1016/j.bmc.2011.07.053 PMid:22079865

28. (a) Stewart, A. O.; Williams, R. M. J. Am. Chem. Soc. 1985, 107, 4289. (b) Humbert, A.; Ple, K.; Harakat, D.; Martinez, A.; Haudrechy, A. Molecules 2012, 17, 7709.

29. Moreno-Clavijo, E.; Carmona, A. T.; Moreno-Vargas. A. J.; Robina, I. Tetrahedron Lett. 2007, 48, 159, and references therein. http://dx.doi.org/10.1016/j.tetlet.2006.10.128

30. Pino-González, M.-S.; Assiego, C. Tetrahedron: Asymmetry 2005, 16, 199. http://dx.doi.org/10.1016/j.tetasy.2004.11.054

31. Moreno-Vargas. A. J.; Carmona, A. T.; Mora, F.; Vogel, P.; Robina, I. Chem. Commun. 2005, 4949.

32. Guillerm, G.; Varkados, H.; Auvin, S.; LeGoffic, F. Tetrahedron Lett. 1987, 28, 535; http://dx.doi.org/10.1016/S0040-4039(00)95775-7.

33. Carmona, A. T.; Fuentes, J.; Vogel, P.; Robina, I. Tetrahedron: Asymmetry 2004, 15, 323. http://dx.doi.org/10.1016/j.tetasy.2003.11.022

34. Robina, I.; Gearing, R. P.;Buchanan, J. G.; Wightman R. H. J. Chem. Soc. Perkin I, 1990, 2622 .

http://dx.doi.org/10.1039/p19900002622

35. Kolb, H. C.; Finn, M. G.; Sharpless, K. B. Angew. Chem. Int. Ed. 2001, 40, 2004. http://dx.doi.org/10.1002/1521-3773(20010601)40:11<2004::AID-ANIE2004>3.0.CO;2-5

36. Tornoe, C. W.; Christensen, C.; Meldal, M. J. Org. Chem. 2002, 67, 3057. http://dx.doi.org/10.1021/jo011148j

37. Meldal, M.; Tornoe, C. W. Chem. Rev. 2008, 108, 2952.

http://dx.doi.org/10.1021/cr0783479

PMid:18698735 